\title{
Ecological Networks in a Changing Climate
}

GUY WOODWARD, JONATHAN P. BENSTEAD,

OLIVER S. BEVERIDGE, JULIA BLANCHARD, THOMAS BREY,

LEE E. BROWN, WYATT F. CROSS, NIKOLAI FRIBERG, THOMAS

C. INGS, UTE JACOB, SIMON JENNINGS, MARK E. LEDGER, ALEXANDER M. MILNER, JOSE M. MONTOYA,

EOIN O'GORMAN, JENS M. OLESEN, OWEN L. PETCHEY, DORIS

E. PICHLER, DANIEL C. REUMAN, MURRAY S.A. THOMPSON, FRANK J.F. VAN VEEN AND GABRIEL YVON-DUROCHER

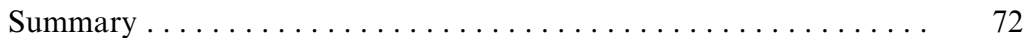

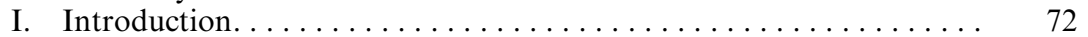

II. The Foundations of a First-Principles Approach. . . . . . . . . . . . 75

A. Individuals, Species and Body Size . . . . . . . . . . . 75

B. Experiments and Surveys at Different Scales and Examples . . . 78

III. Network Responses to Climate Change Components: Impacts of

Warming on Organisms . . . . . . . . . . . . . . . . . . . 87

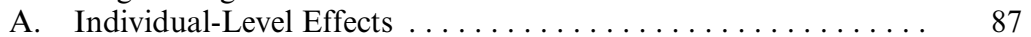

B. Interaction-Level Effects . . . . . . . . . . . . . . . . . . . . . . . 89

C. Population and Community-Level Effects . . . . . . . . . . . . . . 89

D. Individual-to-Network Level Effects . . . . . . . . . . . . . . 91

E. Evolutionary and Biogeographical Effects of Warming. . . . . . . 94

IV. Network Responses to the Components of Climate Change: Impacts

of Warming on Aqueous Media . . . . . . . . . . . . . . . 94

A. Fluid Viscosity: Impacts on Individuals,

B. The Form and Distribution of Water in the Environment . . . . 97

V. Network Responses to the Components of Climate Change:
Atmospheric Composition and Ecological Stoichiometry . . . . . . . 100

VI. Network Assembly and Disassembly: Spatial and Temporal Matches and Mismatches. . . . . . . . . . . . . . . . . . . . . 104

A. Climate Envelope Models, Invasions and Extinctions: Spatial

Rewiring of Ecological Networks . . . . . . . . . . . . . . . . 104

B. Phenological Matches and Mismatches: Temporal Rewiring of

Ecological Networks . . . . . . . . . . . . . . . . . . . 110

VII. Multiple and Interacting Components of Climate Change . . . . . . . 114

A. Combined Impacts of Warming and Atmospheric Change on Metabolism and Stoichiometry Within Ecological Networks . . . 115

B. Other Additive and Synergistic Effects of the Components of

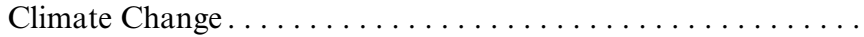


VIII. Conclusions . . . . . . . . . . . . . . . . . . . . . . . . . . 121

Acknowledgements.................................. 122

References...................................... 122

\section{SUMMARY}

Attempts to gauge the biological impacts of climate change have typically focussed on the lower levels of organization (individuals to populations), rather than considering more complex multi-species systems, such as entire ecological networks (food webs, mutualistic and host-parasitoid networks). We evaluate the possibility that a few principal drivers underpin network-level responses to climate change, and that these drivers can be studied to develop a more coherent theoretical framework than is currently provided by phenomenological approaches. For instance, warming will elevate individual ectotherm metabolic rates, and direct and indirect effects of changes in atmospheric conditions are expected to alter the stoichiometry of interactions between primary consumers and basal resources; these effects are general and pervasive, and will permeate through the entire networks that they affect. In addition, changes in the density and viscosity of aqueous media could alter interactions among very small organisms and disrupt the pycnoclines that currently compartmentalize many aquatic networks in time and space. We identify a range of approaches and potential model systems that are particularly well suited to network-level studies within the context of climate change. We also highlight potentially fruitful areas of research with a view to improving our predictive power regarding climate change impacts on networks. We focus throughout on mechanistic approaches rooted in first principles that demonstrate potential for application across a wide range of taxa and systems.

\section{INTRODUCTION}

The Earth's average surface temperature is predicted to rise by $3-5^{\circ} \mathrm{C}$ over the next century, far faster than previously experienced by human civilization (Parmesan and Yohe, 2003; Pounds et al., 1999; Thomas et al., 2004). Even larger increases (up to $7.5^{\circ} \mathrm{C}$ ) are projected for some Arctic regions over the same timeframe based on Global Climate Model simulations (IPCC, 2007). Although there are major uncertainties in these estimates, climate change is nevertheless likely to place considerable environmental stress on many natural systems in the near future (Walther, 2010). Indeed, dramatic changes have already been reported from many ecosystems in recent decades, especially in the Arctic, in the West Antarctic peninsula region and at high altitudes (e.g. Brooks and Birks, 2004; Douglas et al., 1994; Konig et al., 2002; Schofield et al., 2010; Smol et al., 2005) as greenhouse gas emissions and global temperatures have increased. Rising temperatures are just one component 
of climate change, albeit the one most intensively studied by biologists (Walther, 2010; Walther et al., 2002), and changes in atmospheric composition, the physical properties of aqueous media and weather conditions will also alter the physical environment within which ecosystems operate. The effects of climate change on organisms can therefore be direct (e.g. warming increases ectotherm metabolic rates, or stress on physiological systems), indirect (e.g. shrinking and fragmentation of fresh waters during drought, species effects that are mediated by another species) or a combination of both (Woodward et al., 2010b).

Although the effects of climate change will permeate all levels of biological organization, most research has focused on responses at the lower levels of organization (e.g. range shifts in species populations), and only a few studies have considered community- or ecosystem-level impacts (Hickling et al., 2006; Montoya and Raffaelli, 2010; Parmesan, 2006; Sala et al., 2000; Spooner and Vaughn, 2008; van der Putten et al., 2010). Interspecific interactions within food webs or other types of multi-species ecological networks have been largely ignored within the context of climate change research (but see Emmerson et al., 2005a; Harmon et al., 2009; Ims and Fuglei, 2005; Meerhoff et al., 2007; Woodward et al., 2010a). This represents a critical bottleneck in our predictive ability because network-level responses to stressors cannot simply be extrapolated from studying single species in isolation (Kishi et al., 2005; Raffaelli, 2004; Tylianakis et al., 2008; Woodward, 2009). Part of the reason for this current knowledge gap undoubtedly stems from the perception that ecological networks, which may contain thousands of species and tens of thousands of links, are seemingly too complex to be easily predictable (Montoya et al., 2006; Riede et al., 2010). However, there is increasing evidence that structure and dynamics of even very complex networks might be underpinned by a few relatively simple and predictable rules based on foraging and metabolic constraints, and the distribution of interaction strengths (Beckerman et al., 2006; Berlow et al., 2009; Cohen et al., 2003; McCann et al., 1998; Montoya et al., 2006; Petchey et al., 2008; Reuman and Cohen, 2005; Williams and Martinez, 2000). A new perspective that considers the network level of organization, and its links to other levels, is needed to complement the current phenomenological approaches to develop a more general, mechanistic approach to predicting the impacts of climate change (Ings et al., 2009; Montoya and Raffaelli, 2010; Tylianakis, 2009; Woodward et al., 2010b).

Traditionally, the study of ecological networks has focused on consumerresource relations in (mostly aquatic) food webs and terrestrial hostparasitoid systems, but recently this has been broadened by the dramatic surge in research on mutualistic networks (e.g. coral-zooxanthellae symbioses; plant-pollinator systems; plant-seed disperser systems) (Ings et al., 2009; Montoya et al., 2006; Olesen and Jordano, 2002; Olesen et al., 2010). In reality, of course, many ecosystems contain all three network types, 
in addition to competitive interactions, and species may be operating simultaneously within more than one network (e.g. crab spiders that prey upon insect pollinators of flowering plants, which are themselves eaten by herbivores; Ings et al., 2009). The scientific study of these multilayered 'super networks' is still too embryonic to make any firm generalizations at present (Olesen et al., 2010), so the distinctions among the three network types delineated earlier have been retained here for tractability.

Several recent studies and reviews have considered how climate change might affect the higher levels of biological organization (Bascompte and Stouffer, 2009; Wrona et al., 2006), but these have tended to be restricted to considering one type of network (e.g. food webs: Woodward et al., 2010b; plant-pollinator networks: Memmott et al., 2007), one type of system (e.g. terrestrial ecosystems: Tylianakis et al., 2008; running waters: Perkins et al., 2010; marine ecosystems: Hays et al., 2005; Moran et al., 2010; soils: Davidson and Janssens, 2006), one aspect of climate change (e.g. warming: McKee et al., 2003; Yvon-Durocher et al., 2010a,b), or they have emphasized the contingency rather than the potential generality of impacts and responses (e.g. Tylianakis et al., 2008). Here, we aim to improve our currently limited ability to anticipate the effects of climate change on different network types, by attempting to identify emerging components of a research approach that spans multiple levels of organization and is based on general first principles. Consequently, much of the paper concerns how physical and chemical laws (e.g. fluid viscosity, thermodynamics and elemental stoichiometry) that underpin different aspects of climate change act upon individuals and how these effects might be scaled up to predict network-level responses. We also highlight research areas that currently lack general predictive ability at the network level (e.g. species-specific climate envelopes) and discuss to what extent these might be extended and ultimately incorporated into a more predictive, first-principles framework. We identify those systems that are most likely to provide fruitful avenues of further study, and highlight those that seem less promising, in an attempt to help focus future research efforts more efficiently. Finally, we investigate how the different components of climate change (e.g. temperature, atmospheric chemistry), when combined, might act in additive or synergistic ways. Our ultimate objective is to stimulate the development of a novel general theoretical framework to facilitate testable predictions about the likely responses of ecological networks to our changing climate.

Some foundations common to the research approaches we explore are presented in Section II, where we also address the diverse range of methods that will need to be employed. In Sections III-VI, we consider how best to assess the impacts of the different components of climate change we have identified. For each of these components, we identify generalities and remaining contingencies, whilst exploring how effects at lower levels of organization 
can be understood from general principles and aggregated to produce network-level understanding. Section VII considers how the different components of climate change addressed in Sections III-VI might combine and potentially interact to influence network-level responses in additive or nonadditive ways.

\section{THE FOUNDATIONS OF A FIRST-PRINCIPLES APPROACH}

The general approaches we identify, within which researchers are beginning to understand network-level impacts of climate change as the aggregation of better understood, lower level processes, all rely heavily on quantifying individual variation within species. In particular, many are underpinned by the primacy of body size as an easily measured and unifying property of organisms that is strongly linked to metabolism, behaviour and resource acquisition, all of which are key drivers at the network level of organization. These foundational aspects of the several approaches we identify are elaborated in Section II.A, and some of the key relationships of ecological relevance that will be addressed throughout the paper are highlighted in Table 1. In contrast to the cross-cutting importance of body size and an individualbased perspective, a general understanding of the effects of climate on networks will require the use of a wide range of methodological approaches at different spatial and temporal scales, which are considered in Section II.B.

\section{A. Individuals, Species and Body Size}

Ecological networks comprise entities ('nodes') connected to one another by links that represent some form of biological interaction (e.g. herbivory, detritivory, predation, parasitism, pollination) (Ings et al., 2009; Lafferty et al., 2008). Nodes are aggregations of individuals, which are usually lumped together on the basis of taxonomic or functional similarity (Ings et al., 2009; Reiss et al., 2009). The first step towards developing a general framework is to define the relevant entities of interest associated with the nodes and links within a network.

A logical place to start is to use individual organisms, since that is the level of organization at which interactions actually occur, and then to aggregate these entities hierarchically, based on their taxonomic identity or functional roles, to form the network (e.g. Ings et al., 2009; Woodward and Warren, 2007). In contrast to the traditional dichotomy of viewing networks from either a species or size-based perspective, more integrated approaches have 
Table 1 Examples of relationships between key biological and environmental parameters that are size- and/or temperature dependent

\begin{tabular}{|c|c|c|c|}
\hline Ecological phenomenon & Relationship & Network consequence & Examples \\
\hline $\begin{array}{l}\text { Sinking rate versus } \\
\frac{\text { size (volume, } V \text { ) in }}{\text { plankton }}\end{array}$ & $a V^{2 / 3}$ & $\begin{array}{l}\text { Altered consumer ingestion rates and } \\
\text { removal of plankton from euphotic } \\
\text { zone to sediment }\end{array}$ & \\
\hline $\begin{array}{l}\text { Mass-specific } \\
\text { metabolic rate } \\
\left(\text { time }^{-1}\right) \text { versus size } \\
(\text { (body mass, } M)\end{array}$ & $a M^{-1 / 4}$ & $\begin{array}{l}\text { Mass-specific metabolic demands } \\
\text { increase with size ( } \approx \text { trophic status). } \\
\text { Larger species, higher in the food web } \\
\text { have higher metabolic demands than } \\
\text { smaller species at the lower trophic } \\
\text { levels }\end{array}$ & $\begin{array}{l}\text { Peters (1983) } \\
\text { Lopez-Urrutia et al. (2006) }\end{array}$ \\
\hline $\begin{array}{l}\text { Nutrient diffusion } \\
\left.\quad \text { (mol N (cell time) }^{-1}\right) \\
\text { versus size; }(D, \\
\text { molecular diffusivity; } \\
R, \text { cell } \\
\text { radius; } \Delta C \text {, cell } \\
\text { surface nutrient } \\
\text { concentration-bulk } \\
\text { medium nutrient } \\
\text { concentration. }\end{array}$ & $\propto 4 \pi R D \Delta C$ & $\begin{array}{l}\text { If } \mathrm{CO}_{2} \text { uptake is diffusion-limited, large } \\
\text { phytoplankton should be at a } \\
\text { competitive advantage as } \mathrm{CO}_{2} \text { levels } \\
\text { rise: this could shorten pelagic food } \\
\text { chains, if phytoplankton-zooplankton } \\
\text { predator-prey mass ratios remain } \\
\text { constant }\end{array}$ & $\begin{array}{l}\text { Finkel et al. (2010) and } \\
\text { references therein. }\end{array}$ \\
\hline $\begin{array}{l}\text { Population } \\
\text { abundance versus size } \\
\underline{\text { (body mass, } M)}\end{array}$ & $\begin{array}{l}\text { (a) } \approx a M^{-0.75} \\
\text { (b) } \approx M V^{-1}\end{array}$ & $\begin{array}{l}\text { (a) within trophic levels } \\
\text { (b) across trophic levels } \\
\text { Energy flows from abundant, small } \\
\text { species to large rare species within a } \\
\text { trophic network }\end{array}$ & $\begin{array}{l}\text { Brown et al. (2004), but see } \\
\text { Reuman et al. (2008). }\end{array}$ \\
\hline
\end{tabular}


Size-class abundance

$\approx a M^{-0.75}$ versus size; (body mass, $\bar{M})$

Metabolic rate $\left(\right.$ time $\left.^{-1}\right)$
versus temperature

Assuming the use of a common energy source, smaller organisms should be favoured as temperatures rise: slopes may be conserved but intercepts and size ranges may shift (e.g. increased prevalence of small phytoplankton in marine systems Moran et al., 2010)

Energetic demands increase with temperature - this could lead to elevated activity and potential increases in predator-prey encounter rates and interaction strengths
Jennings and Brander (2010); Moran et al. (2010), but see Brown et al. (2004), Reuman et al. (2008)

Woodward et al. (2002a), Brey (2010)

\footnotetext{
Independent variables are underlined (see also Finkel et al., 2010; Woodward et al., 2005b for additional relationships based on first principles).
} 
been advocated recently, in which individuals are not only identified to a high level of taxonomic resolution (i.e. species populations) but also described in terms of their functional role, often based on their body size (Barnes et al., 2008; Ings et al., 2009; Woodward and Warren, 2007; Yvon-Durocher et al., 2010 b). Body size ( $\approx$ body mass) is a useful proxy for many functional attributes (especially in aquatic networks), because it captures a large amount of trophic information in a single dimension and, along with temperature, it largely determines an individual's basal metabolic rate and thus its energy requirements (Ings et al., 2009). A key advantage of employing such individual-based networks is that they can be viewed from alternative perspectives simultaneously, allowing, for instance, the relative importance of taxonomic identity versus body size to be assessed (Petchey and Belgrano, 2010; Woodward et al., 2010c). The role of body size in terrestrial networks is perhaps less clear than in aquatic systems, as seemingly idiosyncratic species traits (e.g. ovipositor or proboscis structure) appear to be relatively more important (Ings et al., 2009; Tylianakis et al., 2008). Nonetheless, it can still be an important descriptor of network structure in host-parasitoid networks (Cohen et al., 2005), terrestrial food webs (Petchey et al., 2002), soil food webs (Reuman et al., 2009b) and even plant-pollinator networks (Stang et al., 2006, 2009).

The fundamental links between body size and metabolism underpin a wide range of allometric scaling relationships that operate from the level of the cell, to individuals, to entire ecosystems (Allen et al., 2005; Atkinson, 1994; Brown et al., 2004; Emmerson et al., 2005b; Peters, 1983; Reuman et al., 2008, 2009a; Woodward et al., 2005a,b). The ubiquity of the size-metabolism relationship offers a useful starting point for developing a general theoretical framework, especially because it is also linked directly to two key components of climate change: altered environmental temperature (Brown et al., 2004; Clarke and Fraser, 2004) and consumer-resource CNP ratios (Allen and Gillooly, 2009), both of which are predicted to change significantly as concentrations of carbon-based gases in the atmosphere continue to rise.

\section{B. Experiments and Surveys at Different Scales and Examples}

Since it is impossible to carry out a replicated study of climate change on a truly global scale, we need to approach the problem in a layered fashion, using a range of techniques and model systems to build towards a general overview (Figure 1). This is a challenging task, not least because research groups typically act in relative isolation from one another and often use their own bespoke approaches to understanding a particular aspect of climate change. In addition, most ecological research is conducted over short timescales and at small spatial scales, due largely to logistical and financial constraints, so there is often a mismatch between the scales at which the 


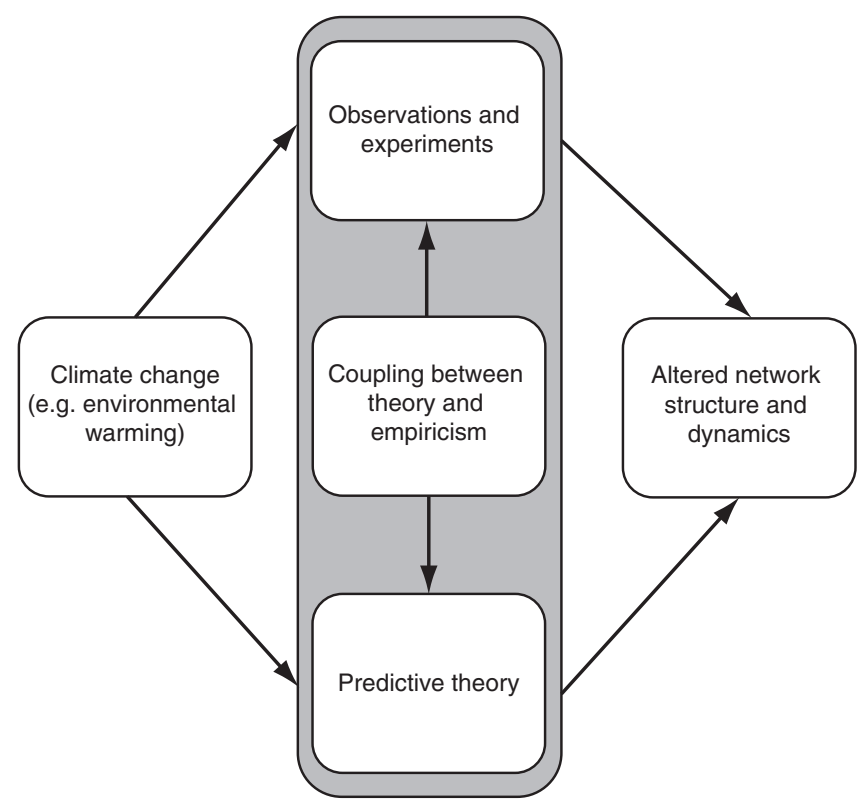

Figure 1 Understanding and predicting the changes in network structure and dynamics that result from climate change (with increasing environmental temperature shown as the example here) require empiricism, theory and close linkage of the two. This link has been made, for example by focusing on the effects of temperature on individuals, their metabolism, their foraging behaviour and other individual level processes. The use of mechanistic models of such effects allows predictions in novel circumstances, which can be validated against observational and experimental studies. Differences between model predictions and empirical results can be used to improve and refine the predictive theory, making the grey shaded region an iterative an continuous process.

environmental drivers operate and the ecological responses are manifested (Kratz et al., 2003; Lane, 1997; Olesen et al., 2010). Ideally, when gauging network-level responses to climate change, studies should run for at least as long as one generation of the longest lived species in the system to take account of as many potential feedback loops as possible because such indirect effects can be critical determinants of how the system responds to perturbations (e.g. Montoya et al., 2009; Yodzis, 1988). The key point here is that time is not absolute per se, but a relative measure based on generation times. Unfortunately, it is unrealistic to run such studies in most natural systems as the requisite time could amount to several decades. Shortcuts or alternative approaches are therefore often necessary, such as reconstructing networks by using space-for-time substitutions (Rawcliffe et al., 2010); 
hindcasting from preserved samples or palaeoecological cores (e.g. Layer et al., 2010a); exploring the impacts of thermal pollution (e.g. Langford, 1990) or geothermal warming in 'natural experiments' (e.g. Friberg et al., 2009; Woodward et al., 2010a); carrying out manipulative field experiments in mesocosms (e.g. Yvon-Durocher et al., 2010a); the use of experimental microcosms and short-lived microbial and protist taxa as model systems (e.g. Petchey et al., 1999); employing in silico simulations (Petchey et al., 2010) or some combination of the above (e.g. Layer et al., 2010b; Montoya et al., 2009).

Space-for-time substitutions represent one of the most widely used approaches in ecological climate change research, but two questions need to be addressed when conducting such studies (e.g. Castella et al., 2001): can spatial snapshots be extrapolated to describe temporal change, and are equilibrial or non-equilibrial conditions being measured? Essentially, both relate to the extent to which ecological responses can keep pace with changing environmental conditions: for instance, transient, non-equilibrial behaviour may be manifested if warming occurs faster than the rate at which the biota can respond, whereas (new) equilibrial conditions may be achieved if the rate of change is relatively slow. Bearing these points in mind, we can identify some idealized criteria for helping to select suitable systems to work with, including: (1) networks should be constructed by direct observation of nodes and links, with body mass, CNP tissue content data and abundance measured, where possible; (2) the system can be perturbed experimentally to simulate some aspect of climate change and to measure its response; (3) measurements of responses can be made at relevant spatial and temporal (generational) scales, across meaningful environmental gradients, and with a minimum of potential confounding effects. In reality, of course, it will often not be possible to meet more than one of these within a given study system. We have identified a sample of several 'model systems' that meet at least some of these criteria and offer potentially promising avenues for future network-based climate change research, which we highlight briefly here and then return to address in more detail later. These systems occupy different portions of the control/realism-replication spectrum, from laboratory-based microcosm experiments to large-scale survey data from close-to-pristine natural ecosystems, such as the Antarctic Weddell Sea food web. This list is not exhaustive and arguably biased towards systems that we are most familiar with, and each has its own advantages and disadvantages, as outlined in Table 2.

At small spatiotemporal scales, laboratory-based experiments with microbial communities provide a high level of control and replication and can be run for many generations over a relatively short time span (weeks to months; Petchey et al., 1999). They have been criticized due to a perceived lack of realism, but nonetheless they represent valuable models for testing cause-and-effect in ways that are not otherwise possible (Daehler and 
Table 2 The tool box of approaches used in the study of ecological networks in a changing climate

\begin{tabular}{|c|c|c|c|}
\hline $\begin{array}{l}\text { Approach [usefulness in } \\
\text { addressing network } \\
\text { responses to climate change] }\end{array}$ & Strengths & Weaknesses & $\begin{array}{l}\text { Examples of commu- } \\
\text { nity/ecosystem/net- } \\
\text { work-level studies }\end{array}$ \\
\hline $\begin{array}{l}\text { Ancient fossil data } \\
\text { [Limited] }\end{array}$ & $\begin{array}{l}\text { 1. True temporal change over } \\
\text { deep time (millions of years) } \\
\text { 2. Ability to identify recurrent } \\
\text { network patterns with } \\
\text { contemporary systems } \\
\text { despite complete species } \\
\text { turnover }\end{array}$ & $\begin{array}{l}\text { 1. Inferential and incomplete } \\
\text { networks } \\
\text { 2. Diets of extinct species } \\
\text { unknown } \\
\text { 3. Species abundances cannot } \\
\text { be quantified accurately }\end{array}$ & Dunne et al. (2008) \\
\hline $\begin{array}{l}\text { Palaeodata } \\
\text { [Limited] }\end{array}$ & $\begin{array}{l}\text { 1. True temporal change } \\
\text { (millennial scales) } \\
\text { 2. Good preservation of many } \\
\text { key taxa (e.g. bones and } \\
\text { scales from vertebrates, } \\
\text { chitin from insects and } \\
\text { pollen or diatom valves from } \\
\text { primary producers) in soils/ } \\
\text { sediment }\end{array}$ & $\begin{array}{l}\text { 1. Potential confounding } \\
\text { gradients and additional } \\
\text { stressors (e.g. post-1850 } \\
\text { eutrophication and } \\
\text { acidification in UK) } \\
\text { 2. Inferred feeding links; } \\
\text { problems with quantification } \\
\text { and selective preservation } \\
\text { (soft-bodied organisms are } \\
\text { often missing from the } \\
\text { record) } \\
\text { 3. Rates of change faster now } \\
\text { than in palaeo record, and } \\
\text { reduced potential for } \\
\text { adaptation due to recent } \\
\text { biodiversity loss }\end{array}$ & $\begin{array}{l}\text { Battarbee (2000), } \\
\text { Rawcliffe et al. } \\
\text { (2010) }\end{array}$ \\
\hline
\end{tabular}


Table 2 (continued)

\begin{tabular}{|c|c|c|c|}
\hline $\begin{array}{l}\text { Approach [usefulness in } \\
\text { addressing network } \\
\text { responses to climate change] }\end{array}$ & Strengths & Weaknesses & $\begin{array}{l}\text { Examples of commu- } \\
\text { nity/ecosystem/net- } \\
\text { work-level studies }\end{array}$ \\
\hline $\begin{array}{l}\text { Contemporary temporal } \\
\text { surveys } \\
\text { [Yes, but } \\
\text { correlational] }\end{array}$ & $\begin{array}{l}\text { 1. True temporal change } \\
\text { (decadal scales) } \\
\text { 2. Nodes and links can be } \\
\text { observed directly for entire } \\
\text { network }\end{array}$ & $\begin{array}{l}\text { 1. Very few suitable long-term } \\
\text { (decadal) data sets. } \\
\text { 2. Potential confounding } \\
\text { temporal gradients (e.g. } \\
\text { acidification, eutrophication) } \\
\text { and other stressors. }\end{array}$ & $\begin{array}{l}\text { Woodward et al. } \\
\text { (2002), Durance } \\
\text { and Ormerod } \\
\text { (2007, 2009), } \\
\text { Milner et al. (2008), } \\
\text { Layer et al. } \\
\text { (2010a) }\end{array}$ \\
\hline
\end{tabular}


Field experiments

[Yes-partial-whole networks]

\section{Lab experiments}

[Yes - partial-whole networks]

Models and simulations [Yes]
1. 'True stressors'

2. Greater degree of control than in surveys - some potential for isolating or combining components of climate change

3. Replication is possible

4. Nodes and links can be observed directly

5. Mechanistic

1. 'True stressors'

2. High level of control than in surveys - ability to isolate or combine components of climate change

3. High replication is possible

4. Nodes and links can be observed directly

5. Mechanistic

1. Long-term dynamics and intergenerational change

2. Isolation of key drivers

3. Mechanistic and predictive

4. Inexpensive
1. Restricted to small spatiotemporal scales (typically intragenerational)

2. Require rigorous assessment of suitability - for example effect size versus spatial

scale $\times$ temperature

3. Partial realism

1. Restricted to small spatial scales

2. Require rigorous assessment of suitability_for example effect size versus spatial scale $\times$ temperature

3. Limited realism/complexity

1. Limited realism

2. Constrained by gaps in theoretical frameworks and data for parameterization (e. g. phenological matchesmismatches)
Hogg et al. (1995), O'Gorman and Emmerson (2009), Woodward and Hildrew (2002a)

Petchey et al. (1999) Woodward and

Hildrew (2002b)

Petchey et al. (2010) 
Strong, 1996). At the opposite end of the control/realism-replication spectrum, long-term surveys of natural systems provide insight into potential responses to climate change in real food webs, but replication is often limited (or nonexistent) and there is the ever-present risk that confounding effects (e.g. eutrophication, acidification) could mask potential responses to climate change (e.g. Durance and Ormerod, 2007, 2009). Long-term biomonitoring programmes of natural ecosystems at appropriate scales (decades to centuries) for detecting climatic signals are extremely scarce. In addition, the time scales over which natural networks have assembled may differ substantially from those at which climate change is now operating and, as a result, space-for-time substitutions can also be prone to potentially confounding spatial or biogeographical effects (e.g. latitude, altitude) (Johnson and Miyanishi, 2008). If these can be minimized, however, such studies can provide important insights with a degree of realism that cannot be captured in experimental studies. Often a combination of approaches can greatly enhance the overall picture: for instance, in empirical surveys of natural systems, Milner et al. $(2000,2008)$ studied glacier retreat through real time over several decades, in addition to using space-for-time substitutions for stream communities in Alaska. Another example of a space-for-time substitution study comes from a catchment of 15 geothermal Icelandic streams that provide a natural experiment for studying the effects of environmental warming in a natural setting, within which field manipulations have also been carried out to disentangle the effects of temperature and nutrient limitation (Friberg et al., 2009; Woodward et al., 2010a). This system is unusual in that all the streams are very close to one another $(<2 \mathrm{~km}$ apart $)$ and embedded in the same stream network, yet each has a characteristic temperature regime over its entire length (ranging from 5 to $25^{\circ} \mathrm{C}$, with one 'outlier' at $44^{\circ} \mathrm{C}$ ), and no additional confounding effects of water chemistry. This allows the effects of temperature to be isolated within a large-scale and long-term 'natural experiment'.

A few intensively studied ecosystems have the dual advantages of possessing extensive time series of data whilst also being amenable to the characterization and experimental manipulation of their ecological networks. Three such model systems include the Ythan Estuary in Scotland (e.g. Emmerson and Raffaelli, 2004), Broadstone Stream in southern England (Hildrew, 2009; Layer et al., 2010b) and Lough Hyne in Southern Ireland (O'Gorman et al., 2008, 2010; O'Gorman and Emmerson, 2010), all of which have been studied for several decades and now have exceptionally well-characterized food webs.

The food web of Broadstone Stream has been studied intensively since the early 1970s: it is strongly size-structured and because encounter rates and hence attack rates increase with temperature, so too do interaction strengths (Hildrew, 2009; Woodward and Hildrew, 2002a; Woodward and Warren, 2007; Woodward et al., 2005a,b). There is some evidence that the food web has altered over four decades in response to an interaction between climatic 
and $\mathrm{pH}$ change. This has been manifested by the invasion and establishment of a new top predator (the dragonfly Cordulegaster boltonii), in the 1990s, followed by the more recent establishment of the first vertebrate (brown trout) (Layer et al., 2010b), which has now usurped the dragonfly as the apex predator. These changes, and similar responses seen in long-term data from other acid freshwaters, have been attributed to an interaction between climate change and an amelioration of acidification (Ledger and Hildrew, 2005; Woodward et al., 2002), as prolonged hot, dry summers reduce acid inputs, opening a window of opportunity for new colonists to establish themselves within the food web (Hildrew, 2009). An intriguing aspect of these data is that these invasions occur at the top of the food web. This is mirrored in the increased predominance of trout in geothermally warmed Icelandic streams (Woodward et al., 2010a), which suggests that warming might reduce energetic constraints on secondary production in these food webs.

Lough Hyne is a large, sheltered marine reserve (Figure 2), in which intensive scientific studies have been ongoing since the late 1920s. A large database of information has built up over this period (Wilson, 1984), with extensive time series data available for some of the key species (e.g. Barnes et al., 2002; Figure 2A). Recent attempts have also been made to quantify the benthic compartment of the food web, combined with investigations of ecosystem functioning and metabolic theory (O'Gorman et al., 2008; YvonDurocher et al., 2008; Figure 2B). Experimental manipulations of experimental food webs within the Lough have shown that larger species have weaker interaction strengths per unit biomass (as opposed to numerical per capita effects) than do smaller species, so the loss of the former taxa, which is often predicted as a consequence of climate change, should result in increased mean interaction strengths and has the potential to destabilize the trophic network (O'Gorman and Emmerson, 2010).

In addition to these 'traditional' food webs that describe interactions between predators and prey and between primary consumers and basal resources, insect host-parasitoid networks also represent useful model systems, particularly because their links can be readily observed and quantified (Ings et al., 2009; van Veen et al., 2006). The typically short generation times of the species involved mean that responses to environmental change can happen quickly, and these systems have already proven useful to measure community-level impacts of land use (MacFadyen et al., 2009; Tylianakis et al., 2007). The population dynamics of host-parasitoid interactions have been studied extensively (Hassell, 2000) and models of pair-wise species interactions have been extended to describe the dynamics of at least simple experimental communities very successfully (Bonsall and Hassell, 1998; van Veen et al., 2005). In principle then, host-parasitoid networks have the potential to provide important insights into how climate change might affect multi-species communities, and to test theoretical predictions in the real 

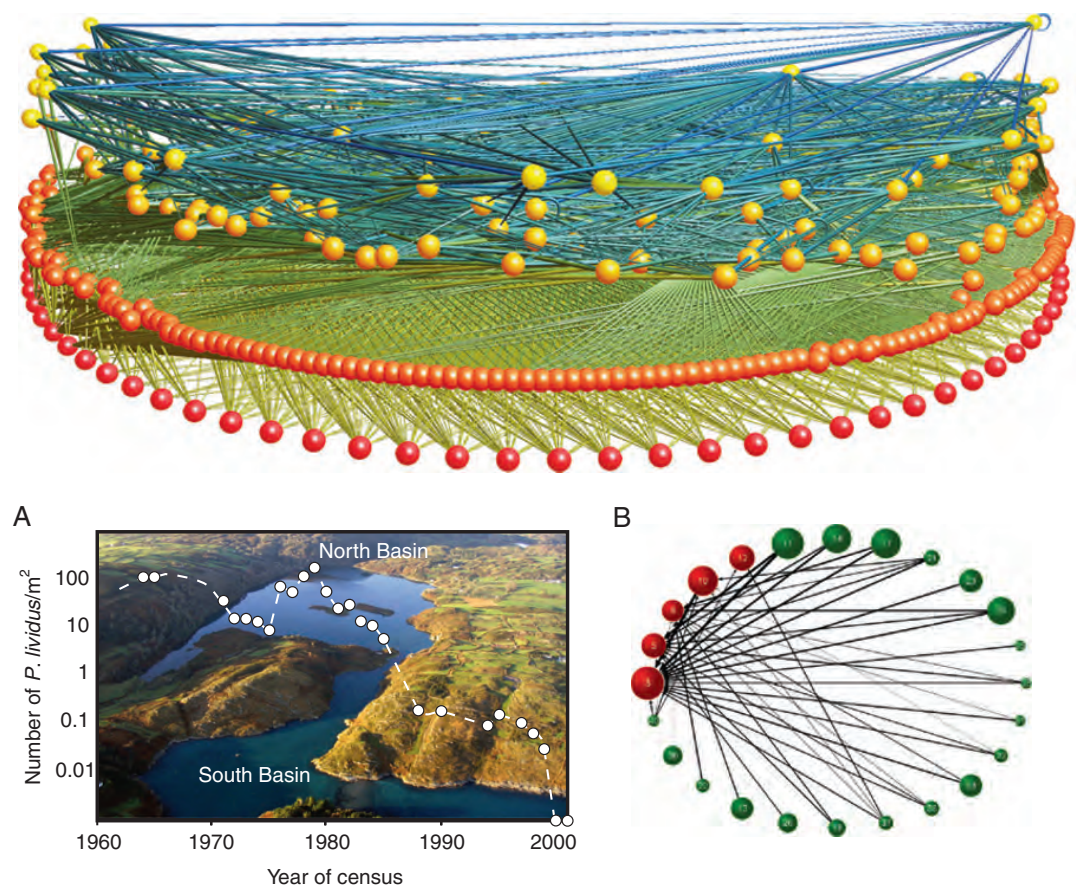

C

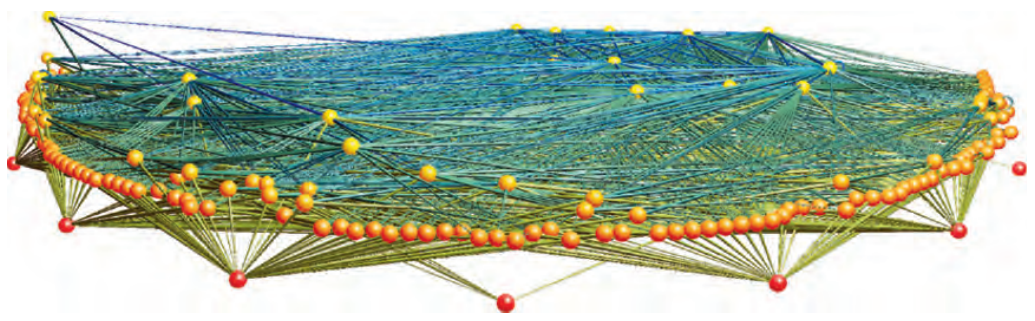

Figure 2 The greater Lough Hyne food web (U. Jacob, unpublished data), highlighting studies using survey-based data versus experimental field trials. (A) Longterm population change in a keystone species within the food web. Population fluctuation of Paracentrotus lividus abundance in the South Basin of Lough Hyne (after Barnes et al., 2002). Insert is the position of Lough Hyne in Ireland. (B) A quantitative portion of the food web from the sublittoral zone is depicted for a guild of predatory fishes and their prey, with the width of arrows representing the strength of the interaction (Yvon-Durocher et al., 2008 for full details) and the size of the nodes representing total population biomass. (C) A subset of 10 consumer species were manipulated in naturally assembling experimental communities as part of a longterm field trial (O'Gorman and Emmerson, 2009). Food webs such as the one shown represent replicable communities that mirror the complexity of the greater Lough Hyne food web. 
world within a feasible timeframe. It must, however, also be borne in mind that there are some important differences between host-parasitoid and predator-prey networks, especially in the degree of diet specialization and hence connectance, due to the nature of the interactions involved, at least in terms of the per capita interaction strengths between consumers and resources (Ings et al., 2009; van Veen et al., 2005), so some caution should be exercised when making wider generalizations based on these systems.

\section{NETWORK RESPONSES TO CLIMATE CHANGE COMPONENTS: IMPACTS OF WARMING ON ORGANISMS}

Environmental warming is probably the most familiar manifestation of global climate change (e.g. Burgmer et al., 2007; Deutsch et al., 2008; Tylianakis, 2009) and its effects have been documented at all levels of biological organization, at least in controlled systems, although most of the research to date has focused on the lower levels. Because of the strong and consistent temperature dependence of many physiological rates (Bystrom et al., 2006; Charnov, 2003; Gillooly et al., 2001; Ings et al., 2009), studying the effects of warming offers promise for developing a systematic approach within which individual-level effects can be scaled up to the network level. For instance, within a network, temperature can have both direct effects (e.g. on the sum of metabolic activity of all individuals in the population) and indirect effects, mediated by their influences on the attributes of organisms and their interactions. Here, we review the current evidence for the effects of warming on individual-level physiological rates, interactions among individuals and populations, and the mostly phenomenological information on its influence at the higher levels of organization. In parallel, we also assess the potential for integration into a general approach and identify some important remaining contingencies that merit further study. These relate mostly to indirect effects of warming through other physical processes, the implications of which, though likely far reaching, are still too poorly understood to be incorporated into any general framework at present.

\section{A. Individual-Level Effects}

Body temperature affects a plethora of individual-level physiological rates, including metabolic rate (Brey, 2010; Clarke and Johnston, 1999; Gillooly et al., 2001), life history milestones (Charnov, 2003; Charnov and Gillooly, 2004), growth (Gillooly et al., 2001), and even rates of nucleotide substitution 
in molecular evolution (Gillooly et al., 2005; but see Lanfear et al., 2007). The effects of warming have now been documented at all levels of biological organization, in laboratory-based microcosms (e.g. Figure 3) as well as in metastudies, and at the individual-level environmental temperature is a strong determinant of reproductive rates (Muller and Geller, 1993), cell size (Atkinson et al., 2003; Richardson and Schoeman, 2004), and movement rates (Petchey et al., unpublished data; Woodward and Hildrew, 2002a). These individual-level responses appear broadly consistent with the effects of temperature on biochemical reactions, as typically described by the Arrhenius relationship (e.g. Brey, 2010; Clarke and Johnston, 1999; Gillooly et al., 2001). The literature on the effects of temperature on individual-level and species-level physiological rates and life-history parameters is large (e.g. Beverton and Holt, 1959; Clarke and Johnston, 1999; Dunham et al., 1989), and we provide only a cursory overview here. In addition, many of the well-known allometric body-size scaling relationships (e.g. Peters, 1983; Yodzis and Innes, 1992) merit augmentation by fitting temperature as an additional component to predict ecological responses (Clarke, 2006). These

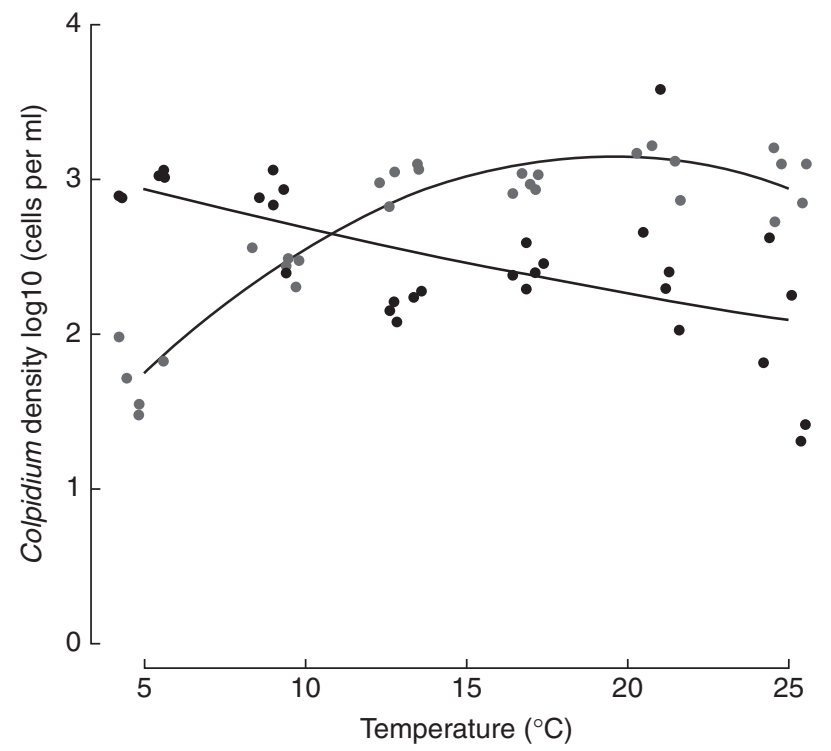

Figure 3 Interspecific interactions fundamentally change the impact of temperature on population dynamics. Grey circles are Colpidium cultured with only bacteria. Black are Colpidium cultured also in the presence of their predator Didinium. Circles are the mean population densities over 2 weeks, lines are statistically significant models (at $p<0.05$ ). An artificial $x$-axis offset has been applied to aid clarity of interpretation. Reproduced with permission from Beveridge et al. (2010) in which full details of the work can be found. 
individual-based relationships have ramifications that filter upwards to the higher levels of organization: for example elevated metabolic rates could increase interaction strengths and hence reduce the dynamic stability of the network as a whole (Kokkoris et al., 2002).

\section{B. Interaction-Level Effects}

Feeding and other interactions between individuals are the final manifestation of a series of discrete steps, each of which is related to physiological rates that can depend on temperature. For feeding to occur, and hence for a trophic link to be manifested within a network, the sequence of these steps ranges from detection, to capture, to consumption of resources, to digestion, each of which is often strongly temperature and size dependent (e.g. Woodward and Hildrew, 2002a). This provides a useful starting point for developing firmer predictions as to how networks as a whole might respond to warming. For instance, because warming tends to increase mobility and activity (especially among ectotherms), attack rates should rise with increasing temperature and handling times should shorten, which will in turn affect ingestion rates and per capita interaction strengths within the network (e.g. Woodward and Hildrew, 2002a,c; Figure 4). Estimates of the activation energies of parasitism rate, attack rate, feeding rate, grazing rate and ingestion rate range from 0.46 to $0.81 \mathrm{eV}$ (Brown et al., 2004; Vasseur and McCann, 2005), and the few data that are currently available suggest that handling times may have activation energies that range from 0.13 to $0.71 \mathrm{eV}$ (Petchey et al., 2010). At present, there is still no firm consensus among the still too-few studies that have estimated the temperature dependence of ingestion (Kingsolver and Woods, 1998; Rall et al., 2010; Sarmento et al., 2010; Thompson, 1978; Woodward and Hildrew, 2002a) and assimilation rates (e.g. Giguere, 1981; Short and Ward, 1981a,b; Zhang and Li, 2004).

\section{Population and Community-Level Effects}

A key question that needs to be addressed at the level of organization of interactions between populations (or size classes) is: does the efficiency of the trophic transfer of biomass from prey to consumer assemblages change with temperature? For instance, the size spectrum of a community allows inferences to be made about trophic transfer efficiency within a food web without the need for direct observations of feeding links, as long as information on predator-prey mass ratios is available (Jennings and Brander, 2010). There is a wealth of size-spectrum data from marine systems, within which size-based (i.e. 'individual size distributions') rather than species-based (i.e. after Layer 


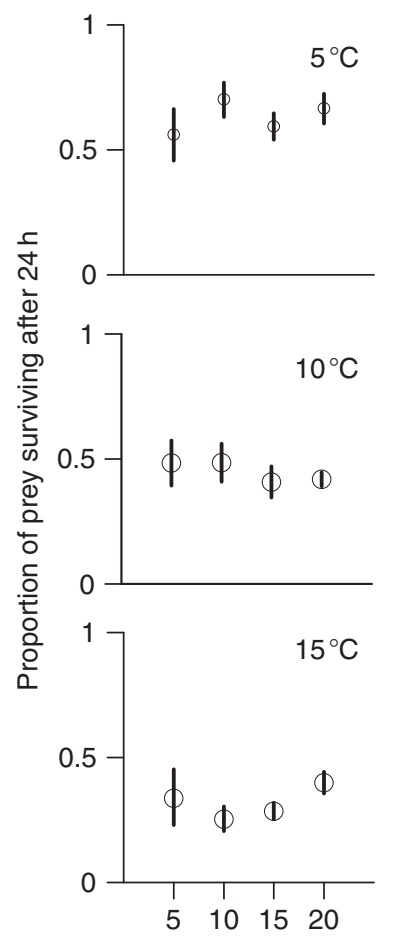

Initial prey density per aquarium

Figure 4 Temperature-dependent changes in interaction strengths between the top predator (the dragonfly $C$. boltonii) and a dominant prey species (the stonefly Nemurella pictetii) within the Broadstone Stream food web. Replicated laboratory experiments were carried out using aquaria maintained at three temperatures: prey survival declined as temperatures increased, due to elevated encounter rates resulting from increased activity levels (redrawn after Woodward et al., 2002a).

et al., 2010b; McLaughlin et al., 2010; O'Gorman and Emmerson, 2010) Mass-abundance $(M N)$ scaling relations have typically been used to infer food web structure and energetics. An in-depth analysis of how mass-abundance scaling relationships and transfer efficiencies might change across temperature gradients ( $v$ across latitude or over long-term series) could offer important insights here, with potentially far-reaching implications for fisheries management (Jennings and Brander, 2010; Perry et al., 2010). There is evidence from correlational studies that $M N$ slopes are surprisingly consistent, even in networks that vary fundamentally in species composition and are found at different temperatures. Boudreau and Dickie (1992), for instance, compared size spectra in a range of aquatic ecosystems and demonstrated that slopes were independent of temperature, whereas changes in intercepts reflected differences in primary production. Marquet et al. (1990) 
and Jonsson et al. (2005) have also provided evidence that $M N$ slopes may be conserved within a narrow range in natural communities, despite considerable turnover in species composition, and that this conservatism appears to be maintained by density compensation coupled with body size shifts. Current evidence seems to suggest that, for a given level of primary production, the size structure, abundance, trophic level and consumer production might be broadly predictable and not strongly temperature dependent (Jennings and Brander, 2010). This implies that if climate-induced changes in primary production can be predicted, and if climate change does not fundamentally alter the rules of community assembly, responses in some properties of consumer assemblages (e.g. changes in the intercept of size-based $M N$ relationships) can be predicted. This size-based approach could provide useful general null models with which to gauge the biological impacts of climate change in multi-species networks, even in the absence of explicitly characterized species populations (Jennings and Brander, 2010), because feeding links can be generalized from predator-prey body mass ratios that do not vary systematically with temperature or primary production at oceanic scales (Barnes et al., 2010).

Moran et al. (2010) have recently combined allometric $M N$ scaling relationships of such individual-based size distributions with the temperaturesize rule to predict an increased prevalence of very small picophytoplankton within the overall marine phytoplankton assemblage as temperatures rise. They found that temperature alone accounted for $73 \%$ of the variance in the relative contribution of these small cells to total phytoplankton biomass, irrespective of differences in inorganic nutrient loading (Moran et al., 2010), suggesting that environmental warming might be the primary driver among the different components of climate change.

\section{Individual-to-Network Level Effects}

At present, the available results at the network-based levels of organization, where nodes and the links between them are described explicitly (rather than implicitly, as in size-spectra approaches), are still largely phenomenological and less unified by theory at present than those at the lower levels. As such, they serve primarily as guides for developing theoretical frameworks that can integrate across levels: ultimately, emerging theory needs to be able to explain observed network-level properties as the outcome of the betterunderstood phenomena manifested at the lower levels of organization. Vermaat et al. (2009) identified connectance, richness and productivity as the three principal components of networks, each of which may be influenced (directly or indirectly) by temperature change. Higher level properties of networks, including the topological or dynamic stability of the system and the role of indirect effects, whereby nodes influence one another 'at a 
distance' (Montoya et al., 2009) are thus likely to be strongly temperature dependent, as are the lower levels of organization that underpin them.

If, for instance, the separate components of the predation sequence do indeed have different activation energies, as suggested earlier, this has implications for the network as a whole. If temperature dependencies vary between the different steps, warming could alter both food web structure (e.g. Petchey et al., 2010) and interaction strengths (e.g. Woodward and Hildrew, 2002a), which are two key determinants of network stability (May, 1972, 1973; McCann, 2000). Recent theory predicts, for example that differential scaling in the temperature dependence of attack rates and handling times will alter the frequency of feeding interactions and, potentially, connectance within a network (Petchey et al., 2010). Such changes have the potential to alter network dynamics, but the current dearth of detailed, standardized empirical data on these temperature dependencies and their effects on network structure makes testing these theoretical predictions impossible at present. This rather surprising gap in our understanding of two fundamental processes (handling times and attack rates) that underpin ecological networks clearly needs to be addressed systematically across a range of systems.

In an experimental study of protist food webs that included information on body size, species identity and feeding links, population extinction caused by gradual warming was much more frequent for larger species than for smaller ones (Petchey et al., 1999), as has also often been predicted for larger metazoans (Raffaelli, 2004; Woodward et al., 2005b). The rate of response and capacity to do so is related to the body size (and thus is also often linked to the trophic level) of the species involved, because larger species have slower turnover times (Woodward et al., 2005b). Experimental manipulations of temperature and food chain length have revealed that the effect of warming on population size depends strongly on the number of trophic levels (Beveridge et al., 2010) and interspecific competition (Jiang and Morin, 2004). Fox and Morin (2001), in contrast, found little evidence of temperature effects on population sizes, let alone interaction-dependent temperature effects. At the network and ecosystem level data are still scant, and few experiments bar that of Petchey et al. (1999) have characterized the responses of even moderately complex communities exposed to temperature manipulations. The increased vulnerability to warming among larger organisms at the higher trophic levels, as predicted by theory and reported by Petchey et al. (1999), appears to contrast with observations from Icelandic geothermal streams, where there was a lengthening of food chains and increased mean individual size and abundance of the largest predators (brown trout) as temperatures increased (Woodward et al., 2010a; Figure 5). This is suggestive that the top predators in cold high latitude and/or altitude systems might be under physiological cold stress (cf. Hari et al., 2006), and as a result they might benefit from bottom-up effects of warming via increased 

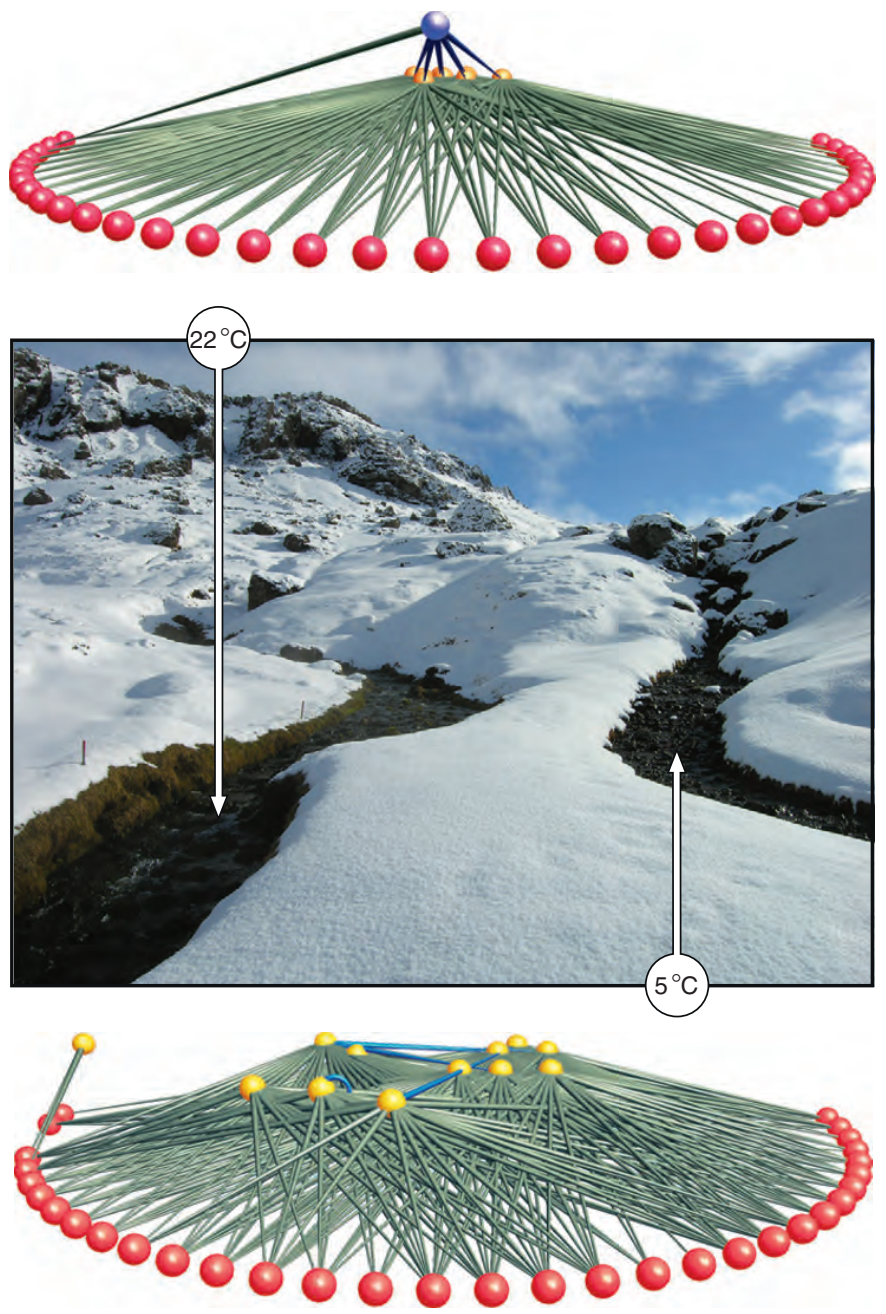

Figure 5 Icelandic stream food webs under ambient conditions $\left(5^{\circ} \mathrm{C}\right)$ and geothermal warming $\left(22^{\circ} \mathrm{C}\right)$, in April 2009 , from within a catchment of 15 streams spanning a wide natural thermal range without additional confounding chemical gradients or dispersal constraints (Friberg et al., 2009; Woodward et al., 2010b). As temperatures increase across streams, the abundance and mean body size of brown trout, the apex predator, increase. The pair of streams exhibit this phenomenon: the cold stream (lower food web) is fishless and omnivorous invertebrates occupy the highest trophic level, whereas trout are the top predators in the adjacent warm stream (upper food web), less than $2 \mathrm{~m}$ away. Food web data: D. E. Pichler et al. (unpublished data).

primary production at the base of the food web (Friberg et al., 2009). The seemingly different network-level responses seen in laboratory microcosms versus those observed in the field clearly merit further exploration from 
an individual-based perspective that can account for the true metabolic costs of operating at different temperatures.

\section{E. Evolutionary and Biogeographical Effects of Warming}

Most ecosystem-level studies have used 'static' temperature differences as a proxy measure of environmental warming, in which systems are maintained at a fixed level above ambient and compared with reference conditions (e.g. Liboriussen et al., 2005; Yvon-Durocher et al., 2010a; Figure 6). Notable exceptions include Petchey et al. (1999), who used a $2{ }^{\circ} \mathrm{C}$ warming per week over 7 weeks in laboratory microcosms, where one week was equivalent to ca. 100 generations of many of the protists within their assembled food webs. Longterm ecological responses to warming will also be accompanied by evolutionary processes (Harmon et al., 2009; Tylianakis, 2009), and there are suggestions that the capacity for adaptation might be impaired at colder temperatures. The suggested reason for this is the link between individual metabolism, generation time and DNA evolution, which has been proposed as a possible explanation of latitudinal gradients in species richness (Allen and Gillooly, 2009; Stegen et al., 2009) and hence the size of local ecological networks. If generation times are too long, this may hinder the ability of populations to turn over and for adaptations to spread fast enough to keep pace with a rapidly changing environment: once again, this should make large species in higher latitude networks particularly vulnerable to warming. It might also partially explain the rapid declines in Arctic char in Lake Windermere in the UK, a cold, deep lake that has seen increases in more eurythermic predatory fish in recent decades (Winfield et al., 2010). If this is a particular example of a more general phenomenon related to an interaction between environmental temperature and long generation times in large, cold-stenothermic species, we might expect to see especially rapid turnover in these higher trophic levels at higher latitudes and altitudes.

\section{NETWORK RESPONSES TO THE COMPONENTS OF CLIMATE CHANGE: IMPACTS OF WARMING ON AQUEOUS MEDIA}

All ecological networks operate within a physical landscape that is itself influenced by temperature: consequently, warming can affect biota both directly (i.e. via metabolic constraints) and indirectly (i.e. via environmental constraints). For instance, climate change will not only influence the viscosity of body fluids and water, but also the form in which the latter occurs in the environment (i.e. vapour, rain, ice) and the amount and timing of its flux 

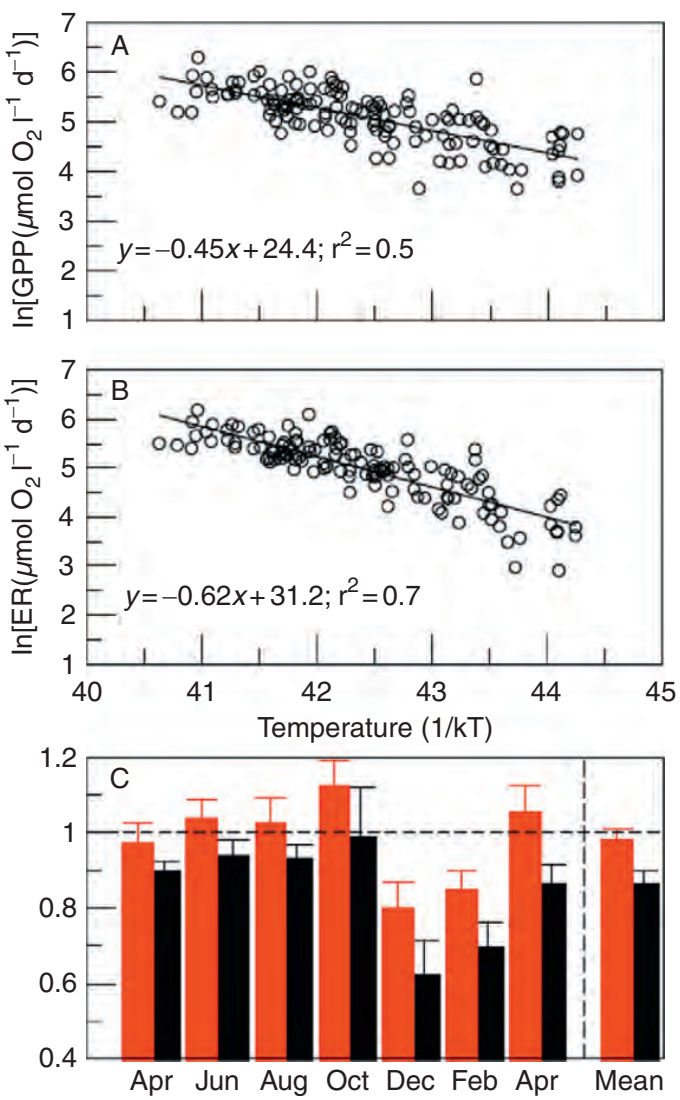

Figure 6 Watching the food web breathe: changes in the 'metabolic balance' (i.e. ecosystem respiration (ER)/gross primary production (GPP)) of pond mesocosms during a one-year warming experiment. The temperature dependences of GPP (A) and ER (B) were significantly different and constrained by the activation energies of photosynthesis and respiration, respectively. As a result, ER increased more rapidly with increases in temperature than did GPP. This shifted the metabolic balance of the warmed mesocosms (grey bars depict warmed treatments and their standard errors, and black bars depict the ambient treatments $\mathrm{C}$ ), resulting in a $13 \%$ reduction in their carbon sequestration capacity that could be predicted from models derived from the MTE. Figure redrawn after Yvon-Durocher et al. (2010a) Note: in (A) and (B) temperature increases from right to left.

through ecosystems (e.g. droughts, floods, glacial meltwaters). Here, we assess temperature-related changes in aqueous media, in terms of its impacts on fluid viscosity and the form and distribution of the occurrence of water in the environment, and the implications of these more indirect consequences of warming for different levels of biological organization. We leave aside other 
important effects of climate change in aquatic systems, in particular ocean acidification resulting from increasing dissolved $\mathrm{CO}_{2}$, whose effects even at the population level are still poorly understood (Pelejero et al., 2010).

\section{A. Fluid Viscosity: Impacts on Individuals, Interactions and Networks}

Fluid viscosity and solute solubility are temperature dependent and, since all living organisms are composed primarily of aqueous fluids, warming will affect the supply and removal rate of key nutrients and waste products to and from body tissues (at least for ectotherms), unless biological mechanisms can countermand these physical changes to an individual's internal environment. By extension, environmental warming also has important implications for the physical properties of the external media within which ecological networks operate, especially in aquatic systems, where the viscosity of the medium will affect buoyancy and sinking rates-and hence encounter rates between consumers and resources. The sinking velocity of phytoplankton, for instance, increases with cell volume according to Stoke's law, described as $\propto a V^{2 / 3}$ (Finkel et al., 2010; Table 1). A change in water temperature from 5 to $10^{\circ} \mathrm{C}$ is associated with a change in viscosity (dynamic) from $1.52 \times 10^{-3} \mathrm{~N} \mathrm{~s} \mathrm{~m}^{-2}$ to $1.31 \times 10^{-3} \mathrm{~N} \mathrm{~s} \mathrm{~m}^{-2}$. The implications of this depend on the organism's size and speed, which can be summarized by the Reynolds number, $\operatorname{Re}$ (a ratio between the inertia of water being displaced and the viscosity of the environment) (Purcell, 1977). Large, fast-moving organisms (Re $>450)$ operate in the inertial regime and are relatively unaffected by changes in viscosity, whereas small, slow-moving organisms $(R e<1)$ operate in the viscous regime and are highly susceptible to changes in viscosity (Sommer, 1996). The diel vertical migration of plankton, and hence consumer-resource encounter rates could be disrupted in pelagic food webs, especially for the smallest organisms at the base of the food web with the lowest Reynolds numbers. Reduced viscosity will reduce the costs of swimming even as it supports faster rates of sinking, so the balance between the effects of viscosity on passive sinking versus active swimming could be critical in determining the strength of interactions among the planktonic organisms at the base of many aquatic food webs. Because changes in viscosity and resultant changes in sinking rates and in the energetic costs of swimming follow known formulas, these effects on aquatic systems could and should be addressed via a systematic theory.

Aquatic networks often comprise basal resource species of phytoplankton or microbial decomposers, and small actively swimming consumers, which have an $R e$ less than one (Sommer, 1996). Diel vertical migration of phytoplankton and the motility of bacteria (Schneider and Doetsch, 1974), protists (Winet, 1976), copepods (Larsen et al., 2008), rotifers (Hagiwara et al., 1998), 
echinoderms (Podolsky and Emlet, 1993) and even fishes (Hunt Von Herbing and Keating, 2003) all depend upon the viscosity of water. Many lower trophiclevel organisms use cilia or flagellae for locomotion or feeding, the beat frequency and displacement of which are determined by density of the surrounding water (Machmer, 1972; Riisgård and Larsen, 2007; Sleigh, 1956), adding to the potential impacts of temperature-dependent changes in viscosity on aquatic communities. Additionally, the interference caused to Daphnia feeding on cyanobacteria by the latter's filaments declines with increasing viscosity (Abrusàn, 2004). Hence, consumer-resource encounter rates and dynamics may change in response to changes in viscosity, in addition to the direct effects of temperature per se. Indeed, the feeding or ingestion rates of several aquatic organisms are known to decrease with increasing viscosity (Abrusàn, 2004; Bolton and Havenhand, 1998, 2005; Loiterton et al., 2004; Podolsky, 1994), and these effects may even be sufficient to qualitatively alter population dynamics (Harrison, 1995; Luckinbill, 1973; Seuront and Vincent, 2008).

Laboratory experiments have manipulated the viscosity of water via the use of thickening agents such as methyl cellulose, polyvinylpyrrolidone (PVP), Dextran, and Ficoll, which has enabled the viscosity-based effects of warming to be isolated from those associated with temperature per se (e.g. changes in metabolic rate). For example Podolsky (1994) quantified the proportion of feeding rates of echinoderm larvae (Dendraster excentricus) that were attributable to temperature-dependent changes in viscosity at $22^{\circ} \mathrm{C}$ (viscosity $=1.02 \mathrm{cP}$ ), $12{ }^{\circ} \mathrm{C}$ (viscosity $=1.30 \mathrm{cP}$ ) and $22^{\circ} \mathrm{C}$ with the addition of Dextran, resulting in a viscosity $1.30 \mathrm{cP}$. This study revealed that the $10{ }^{\circ} \mathrm{C}$ reduction in temperature was associated with a $67 \%$ reduction in feeding rate, $61 \%$ of which was directly attributed to changes in viscosity. In running waters, the ability to resist shear stress, particularly among small organisms, will decline if the viscosity of water increases (Statzner et al., 1988), and in terrestrial plant-pollinator networks nectar might become too 'sticky' for some smaller insects to handle effectively. In flowers with an open morphology, nectar concentration and hence viscosity increase with temperature, and this may change the composition of the visitor fauna, in addition to lowering harvesting rates (Borrell, 2006).

\section{B. The Form and Distribution of Water in the Environment}

The rates and extent of warming predicted under the IPCC (2007) climate change scenarios will not be uniform over space and time, and ecological responses will therefore depend to a large extent upon the physical environment within which they are played out. At the whole-ecosystem scale, the nature and size of the medium within which the ecological network operates will determine its response to rising atmospheric temperature. For instance, large water bodies, such as the open oceans, have sufficiently high heat 
capacity and thermal inertia to smooth out short-term temperature fluctuations, which are also predicted to increase with warming (i.e. both the mean and variability of temperature are likely to rise in many areas, IPCC, 2007). In contrast, small water bodies exposed to direct insolation can fluctuate by tens of degrees Celsius over the course of a single day. For instance, water temperatures in streams fed from small springs or surface run-off (Figure 7)
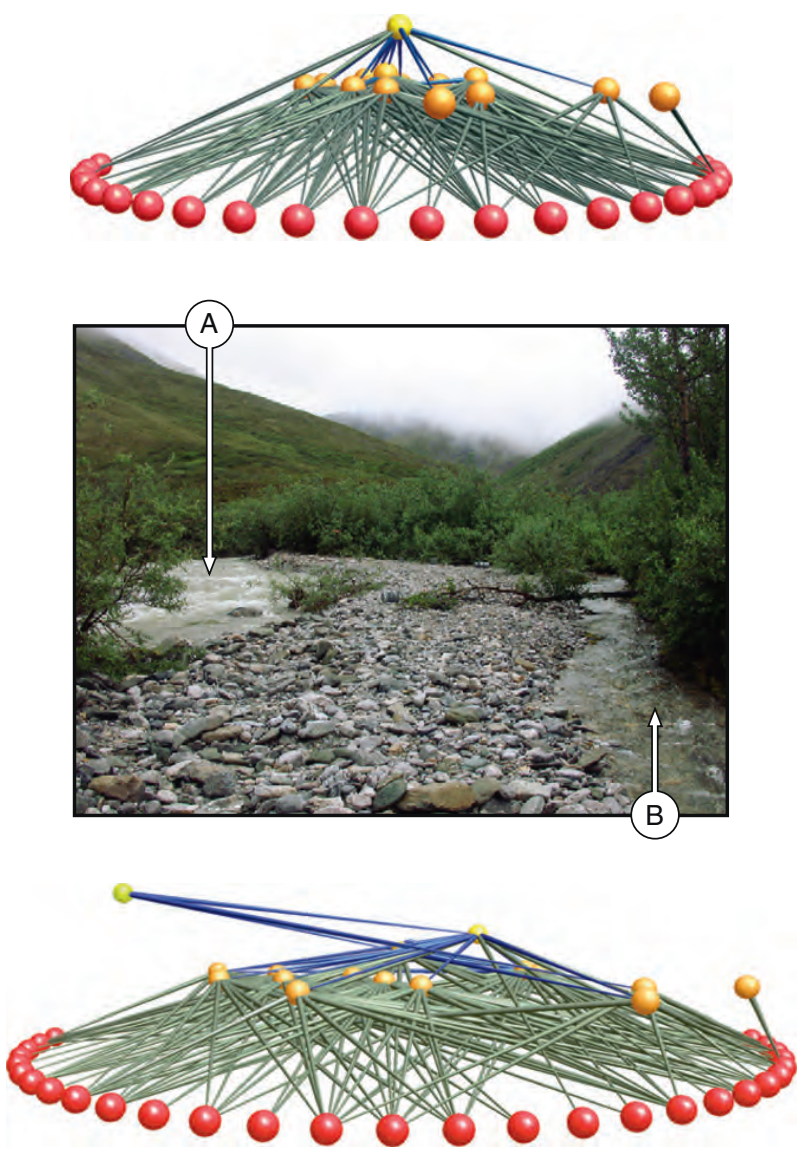

Figure 7 Mountain and spring-fed stream food webs for tributaries of the Ivishak River in arctic Alaska $\left(69^{\circ} 1^{\prime} \mathrm{N}, 147^{\circ} 43^{\prime} \mathrm{W}\right)$ (redrawn after Parker and Huryn, 2006). Mean food chain length was 3.04 in the spring stream and 1.83 in the mountain stream. A fish species, the Dolly Varden char (Salvelinus malma), was the top predator in the mountain stream, whereas an invertivorous riverine bird species, the American dipper (Cinclus mexicanus), was the top predator in the spring stream. Difference in mean food chain length between streams was due largely to the presence of C. mexicanus at the spring stream. 
are far more variable than those supplied by large reserves of groundwater. The latter typically have very stable thermal regimes that reflect their subterranean provenance (e.g. cf. Friberg et al., 2009; Parker and Huryn, 2006; Woodward et al., 2010a). Non-geothermally influenced streams rarely exceed $29^{\circ} \mathrm{C}$ because at elevated air temperatures the vapour pressure deficit above the water surface increases drastically, causing strong evaporative cooling (Mohseni and Stefan, 1999) that sets an upper limit to the ultimate temperature they can attain. In contrast, because maximum temperature is not limited in terrestrial ecosystems in this way, we might expect to see stronger metabolic constraints operating on individuals within terrestrial networks, relative to their aquatic counterparts, as atmospheric temperatures rise in the Tropics.

One profound effect of warming on the physical environment is the "habitat fragmentation' that can arise within waterbodies where pycnoclines delineate sharp gradients of water density. A classic example of this is the widespread phenomenon of thermoclines in aquatic systems, which separate the warm surface waters in the euphotic zone from the cooler and less productive deeper waters in lakes and oceans, with the latter also commonly exhibiting haloclines of differing density and hence viscosity (Gnanadesikan, 1999). Many standing waters and oceanic regions are likely to become more strongly stratified as temperatures rise, and the development and persistence of strong thermoclines could impair the recycling of nutrients to the photic zone from deeper, colder waters (Finkel et al., 2010) by preventing vertical mixing in the water column. The thermal imbalances resulting from predicted surface water warming in the coming decades might ultimately lead to largescale changes in the existing ocean circulation currents, such as the posited change in the Pacific Ocean from today's ENSO (El Niño Southern Oscillation) to a permanent El Nino or La Nina state (Timmermann et al., 1999; but see Sarmiento et al., 2004). At present, on a global scale, pycnoclines tend to disappear in the open ocean at around $50-60^{\circ}$ latitude, due to reduced salinity and/or temperature change, whereas further from the poles they prevent extensive mixing and help to retain the relative biological distinctness of the food webs in different waterbodies. The physical vertical segregation of waters of different density and temperature created by pycnoclines has implications for individual organisms and their interactions within networks. As sinking rates of plankton are positively correlated with body size (which also determines which consumer species exploit the plankton), and since warming should favour smaller phytoplankton (e.g. Moran et al., 2010; Strecker et al., 2004), changes in the vertical depth and horizontal distribution of pycnoclines due to warming could alter food chain lengths, network structure and the flux of nutrients in many lakes and regions of the open oceans. We return to consider these potential interactions between temperature, viscosity and nutrient fluxes within food webs in more detail in Sections $\mathrm{V}$ and VI. 
At high latitudes and altitudes, ice sheets and glaciers are in rapid retreat in many parts of the world, leading to the changes in total runoff volume, the timing of spring/summer runoff peaks and the contributions from different water sources (Milner et al., 2009). Changes in rainfall patterns will alter many terrestrial and freshwater ecological networks, but these effects will be far from uniform across the globe (Boulton, 2003). For instance, the hotter, drier summers and wetter winters predicted for many temperate areas in the near future will create more intense and frequent floods and droughts (Milly et al., 2006), whereas at higher latitudes and altitudes floods could increase in spring and early summer due to more rapid snowmelt (Barnett et al., 2005; Hannah et al., 2007). New hydrologic disturbance regimes have the potential to alter the rate and magnitude of supply of basal resources to primary consumers to eliminate sensitive species and, hence, to restructure entire networks. Some recent long-term experiments have shown that drought episodes can have powerful effects on the organization and functioning of stream food webs (e.g. Harris et al., 2007; Ledger et al., 2009; Walters and Post, 2008). For example in a twoyear field manipulation, repeated droughts reduced the availability of basal resources (Ledger et al., 2008), eliminated members of the consumer assemblages (especially large, rare species high in the food web: Figure 8) and thereby suppressed total secondary production by more than $50 \%$ (Ledger et al., unpublished data). The fragmentation of freshwaters during droughts can break network linkages in both space and time (Zwick, 1992), with large species being affected disproportionately more strongly than smaller, more $r$-selected species, which may benefit, at least temporarily, from the release of top-down or competitive control as suggested by population irruptions during recolonization when the water returns (e.g. Ledger and Hildrew, 2001). Although it may be possible to make some generalizations, because of these apparent system-specific contingencies in their effects on different species and other network components, it is difficult with our current understanding to incorporate hydrological changes into any general or predictive theory at present.

\section{NETWORK RESPONSES TO THE COMPONENTS OF CLIMATE CHANGE: ATMOSPHERIC COMPOSITION AND ECOLOGICAL STOICHIOMETRY}

In addition to the direct and indirect effects of warming, elevated environmental $\mathrm{CO}_{2}$ concentrations associated with climate change could also alter the structure and dynamics of ecological networks fundamentally. One of the key mechanisms of relevance here is the way in which increasing $\mathrm{CO}_{2}$ will 

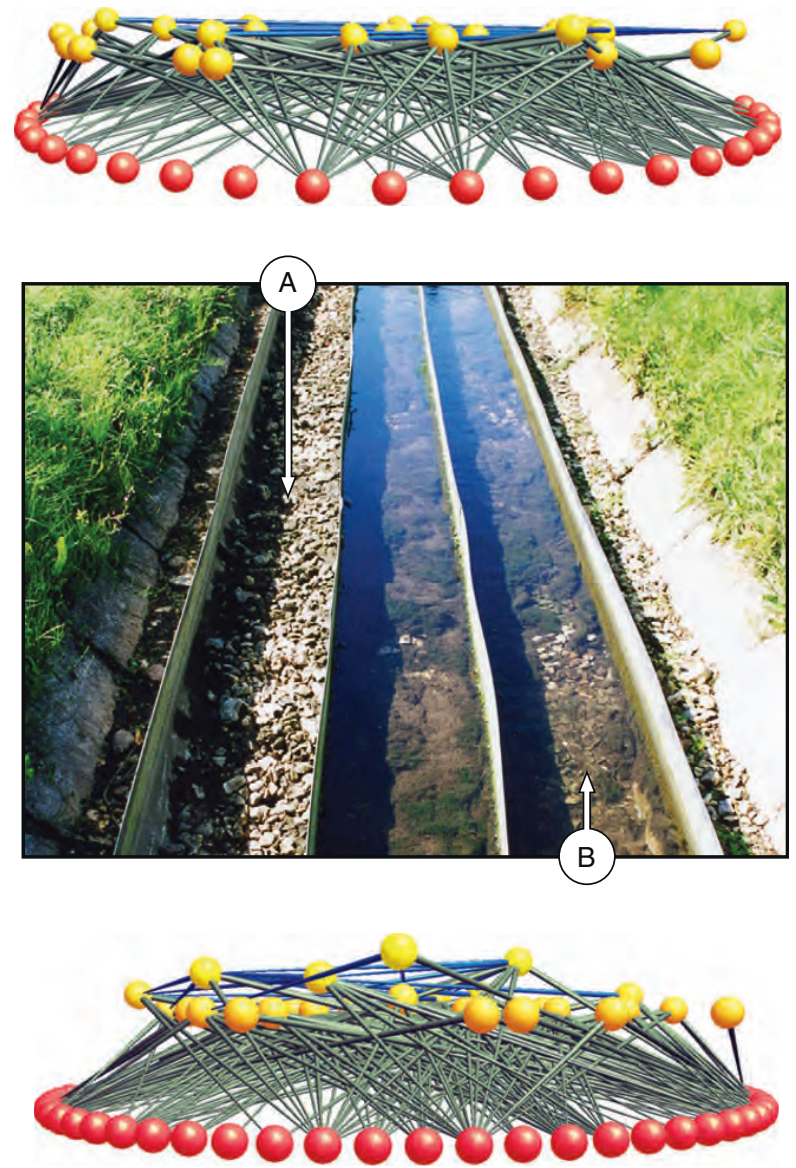

Figure 8 Control (right-hand channel, B, in the photograph) and monthly dewatered (left-hand channel, A) food webs for two experimental stream channels, constructed at the end of a 22-month hydrological manipulation conducted by Ledger et al. (2009). Taxa that became locally extinct tended to be rare and high in the food web, and the network became simpler as species and links were lost in response to drought stress (food web data: M. Ledger et al., unpublished data).

influence the cellular composition of primary producers, which typically have CNP ratios that reflect ambient environmental concentrations (Elser and Hessen, 2005; Kominoski et al., 2007; Redfield, 1934). Changes in environmental $\mathrm{CO}_{2}$ concentrations will alter the elemental composition of $\mathrm{C}$ :nutrient ratios in autotrophs (Hessen et al., 2004, 2005; Urabe et al., 2003), which possess considerable stoichiometric plasticity relative to their more 
homeostatic consumers (Sterner and Elser, 2002). RuBisCO (Ribulose-1,5bisphosphate carboxylase oxygenase), the enzyme that catalyses $\mathrm{CO}_{2}$ fixation, is typically less than half saturated at current global atmospheric $\mathrm{CO}_{2}$ concentrations for most phytoplankton (Badger et al., 1998; Giordano et al., 2005). This is typically the rate-limiting step in the Calvin cycle, so increases in this greenhouse gas have the potential to alter rates of $\mathrm{CO}_{2}$ assimilation dramatically, particularly in the global ocean where the lion's share of the planet's carbon fixation takes place (Cox et al., 2000). Experiments have revealed that algae grown at a range of dissolved $\mathrm{CO}_{2}$ concentrations differ markedly in their stoichiometry, with those grown at high $\mathrm{CO}_{2}$ and low $\mathrm{P}$ exhibiting faster photosynthetic rates but high atomic C:P ratios, which reduced the efficiency of energy and mass transfer to their consumers (Urabe et al., 2003). These stoichiometric shifts among primary producers can be explained by changes in sub-cellular metabolism, as under high $\mathrm{CO}_{2}$ photosynthesis, carbon fixation and assimilation are stimulated, resulting in greater allocation to storage of $\mathrm{C}$-rich sugars relative to P-rich ribosomes required for rapid growth (Urabe et al., 2003).

Heterotrophs are typically far more homeostatic in their stoichiometry than is the case for autotrophs (Sterner and Elser, 2002). As a result, changes in the food quality of basal resources (as defined by their $\mathrm{C}$ : nutrient ratios) can exert strong influences on consumer production and abundance within the food web (Norby et al., 2001). For example Urabe et al. $(2002,2003)$ and Hessen et al. (2002) have shown that growth rates of herbivorous Daphnia decline markedly when fed on high C:P versus low C:P algae. These studies highlight how stoichiometric consumerresource imbalances resulting from increased $\mathrm{CO}_{2}$ could ramify to the network level of organization, as a consequence of changes in autotrophic stoichiometry at the base of the food web. Similarly, elevated $\mathrm{CO}_{2}$ in a 9 -year field experiment in a terrestrial system revealed suppressed herbivore abundance, but increased ingestion rates, reflecting the need of consumers to eat more plant material to extract a similar level of nutriment when C:nutrient levels increase (Stiling and Cornelissen, 2007). Large shifts in the stoichiometry of basal resources with climate change are thus likely to alter the distribution and fluxes of biomass within many food webs, in both terrestrial and aquatic systems. Because the effects of stoichiometry on individuals and interactions have been much studied (e.g. Sterner and Elser, 2002) and the field continues to expand rapidly, there is considerable potential for integrating these effects more deeply into an overall theory to explain network effects of climate change based on lower level principles.

Body size is once again revealed as a potentially important determinant of responses to climate change, as it also influences uptake rates and the 
stoichiometric effects of increased $\mathrm{CO}_{2}$. For instance, phytoplankton cell size, elemental requirements and composition constrain resource uptake and processing rates (see Finkel et al., 2010 and references therein). In many marine systems, phytoplankton body size tends to increase with nutrient availability, so elevated $\mathrm{CO}_{2}$ should favour larger organisms (the opposite of the case for warmer temperatures; Daufresne et al., 2009; Strecker et al., 2007). In turn, increased phytoplankton cell size under elevated $\mathrm{CO}_{2}$ will increase sinking rates and hence could reduce the ability for consumers to recycle carbon before it is lost to the sediment: because large phytoplankton tend to be grazed by large zooplankton (e.g. Cyr and Curtis, 1999) the resultant food webs should be shorter, as fewer trophic steps are required to reach consumers of a given body size, but a higher proportion of primary production could be lost before it is consumed, due to faster sinking rates. Since most of the organic carbon exported to the deep sea is derived from larger, denser cells that sink more rapidly (Laws et al., 2000), the size structure of planktonic assemblages has important consequences for how climate change influences consumer-resource stoichiometry, the flux of energy through the food web and, ultimately, the ability of the global ocean to absorb and store atmospheric $\mathrm{CO}_{2}$ (Kohfeld et al., 2005; Sarmiento and Wofsy, 1999; Watson and Orr, 2003). Scaling relationships between phytoplankton cell size and key ecological and physiological processes have recently been used to model primary production, carbon pools and rates of export to the deep ocean (Finkel et al., 2010), highlighting the importance of understanding these fundamental links between body size, metabolism and elemental fluxes within ecological networks.

In addition to the trophic links between primary producers and herbivores, many ecosystems rely heavily on inputs of energy and nutrients via detrital pathways (e.g. soil food webs), often via external subsidies (Moore et al., 2004). Consequently, the C:nutrient content of detrital resources, which are largely derived from dead primary producers, should also increase as atmospheric $\mathrm{CO}_{2}$ levels rise. These ratios are key drivers of many ecosystem processes associated with decomposition (e.g. Hladyz et al., 2009; Norby et al., 2001; Tuchman et al., 2002) and, ultimately, the fluxes of energy and nutrients to the higher trophic levels within food webs. Carbon-rich detrital resources can also serve to modulate the potentially destabilizing effects on network structure of 'fast' autochthonous food chains based on primary production (Rooney et al., 2006). It remains to be seen how the interplay between these two types of trophic pathway will respond to climate change, but some initial studies suggest that elevated $\mathrm{CO}_{2}$ can shift the balance from the relative importance of algae versus detritus to the higher trophic levels (e.g. Kominoski et al., 2007). 


\section{NETWORK ASSEMBLY AND DISASSEMBLY: SPATIAL AND TEMPORAL MATCHES AND MISMATCHES}

\section{A. Climate Envelope Models, Invasions and Extinctions: Spatial Rewiring of Ecological Networks}

To date, the effects of environmental change on species distributions have been predicted primarily using 'habitat modelling' and 'climate envelope' approaches. In both cases, a species' future distribution is predicted from knowledge about its current distribution, the environmental conditions within that distribution and predictions about future environmental conditions (Pearson and Dawson, 2003). The majority of these modelling approaches do not, however, consider species as interacting components of a wider ecological network (Kissling et al., 2010): rather, they assume that each species experiences completely independent effects of environmental change in isolation. This represents a major shortcoming, given the powerful effects network structure and dynamics have on the ability of organisms to colonize and establish themselves within an ecosystem. Networklevel responses are more than simply the aggregate sum of all their component species-level responses and, as such, the latter cannot simply be extrapolated to predict the former (Tylianakis, 2009; Woodward, 2009).

Making predictions about network assembly based on a species-by-species perspective will be challenging given that the recipient network governs the likelihood that incoming species and life history stages will become established, whilst the incoming organisms also rewire and hence shape the network. Consequently, understanding the patterns and processes that govern network assembly will be crucial in determining the potential impacts of climate change. The key driving forces behind network assembly and disassembly are immigration, speciation and environmental filtering (Weiher and Keddy, 1999). As new habitats are created or old habitats are altered through climatic events, such as environmental warming, changing ocean currents, ice scouring, droughts or flooding, these factors will determine how species and links are gained or lost from the network. Immigration and speciation will be governed by the spatial and temporal dynamics of the system. If species adapted to new environmental conditions already exist nearby, the primary mechanism for assembly will be colonization. Dispersal ability plays a key role here, and certain taxa in particular systems (e.g. aquatic organisms without flying adult stages in landlocked lakes, East-West oriented river networks or freshwaters in small oceanic islands) will have little opportunity to track poleward warming by invading new networks (Ings et al., 2009; Woodward and Hildrew, 2002b). If the environment is sufficiently isolated from source populations of potential new species, network assembly is more 
likely to be fulfilled by evolution or adaptation of existing species through time (Emerson and Gillespie, 2008). Environmental filtering may lead to network disassembly, if certain species can no longer tolerate altered biotic or abiotic factors in the locale, and this could overpower the effects of stochastic processes predicted by neutral theory, for example birth, death, colonization, speciation (Chase, 2007).

In the absence of barriers to migration, range shifts and expansions will lead to the arrival of new species in local communities as climate changes (Rahel and Olden, 2008). Through the links that these species forge in the network, they can have direct and indirect effects on many other species in the community (Henneman and Memmott, 2001) and hence the structure and thereby the stability of the entire web (Romanuk et al., 2009). Nonindependent responses of species to environmental change provide the potential for complex effects on patterns of community assembly and disassembly, and evidence from small-scale experiments suggests that indirect effects of temperature change can be substantial (Davis et al., 1998). This growing body of evidence makes it increasingly clear that it is no longer tenable to make simple predictions about networks based only on species' climate envelopes; rather, the species that can invade or go extinct are dependent not only on changes in environmental conditions, but also on the other species that have invaded already, or have gone extinct already.

In addition, new species assemblages may emerge due to the differential rates of range shifts by species within ecosystems: present assemblages of interacting populations will not simply shift further north or to the west or to higher altitudes. Some species will move faster and further than others. Short-lived species with high dispersal abilities will re-assemble differently within networks from those which are long-lived and have low dispersal potentials (Montoya and Raffaelli, 2010). Spatial dislocations will have important impacts for above-ground versus below-ground terrestrial assemblages, which, although intimately linked, are characterized by quite different rate processes, and could become dislocated as ranges shift through climate change. An example is the effects of such dislocations on future plant distributions and diversity, which might explain why some plants may be lost, whereas others may become more abundant, in their native versus new ranges owing to climate change (Van der Putten et al., 2010).

Despite the strong effects interspecific interactions and network structure can have on community assembly (e.g. Warren, 1996), there are still few studies of how environmental change affects the rate and trajectory of assembly, and fewer still of disassembly (González, 2000), to be able to make reliable generalizations at present. Although not explicitly linked to climate change effects per se, a recent whole-network study was carried out in a series of large subtidal mesocosms in Lough Hyne to explore empirical patterns and processes related to food web assembly and disassembly 
(O'Gorman and Emmerson, 2009, 2010). Identical core assemblages of predatory fish, decapods and echinoderms were established within the cages. Smaller species from lower trophic levels were allowed to recruit naturally, creating multiple replicates of complex food webs consisting of over 100 species. Targeted species extinctions carried out on subsets of the mesocosms highlighted the importance of both strong and weak interactors for food web stability (O'Gorman and Emmerson, 2009; Figure 2C), with cascading effects of strong interactors on ecosystem processes being dampened in the presence of weakly interacting species. Further, the loss of either strong or weak interactors increased the variability of ecosystem process rates and reduced the resistance of the communities to secondary extinctions and invasions. Given that the strong and weak interactors manipulated in this study were the largest species present in the webs, occurring at high trophic levels, these targeted extinctions mirror the loss of large species predicted by climate change scenarios and thus highlight the potential impacts of such losses on network stability (e.g. Raffaelli, 2004).

Some additional evidence for potential changes to freshwater networks under future climatic scenarios can be drawn from a range of studies conducted along temporal and spatial (altitudinal or latitudinal) environmental gradients as proxies for climate change (e.g. Friberg et al., 2009; Lavandier and Décamps, 1983; Parker and Huryn, 2006; Woodward et al., 2010a). In the Alaskan study of Parker and Huryn (2006) (Figure 7), higher streambed disturbance, due to more frequent and intense peak flows arising precipitation-based flow (rather than spring-derived), reduced mean food chain length, altered the identity of top predators and the proportion of biomass at different trophic levels, and significant differences in material and energy flow. Some glacially influenced streams will warm as ice masses shrink in response to climate change, which is generally predicted to increase overall invertebrate diversity whilst simultaneously facilitating the local extinction of cold-stenotherm taxa. However, Flory and Milner (1999) showed that the extinction of an early-colonizing chironomid genus (Diamesa), however, was not due to increased water temperature per se, but to competitive exclusion by another chironomid, Pagasia partica, which colonized later, indicating that warming strengthened biotic interactions, thereby influencing network assembly indirectly. Nevertheless, Milner et al. (2008) showed in a long-term study of a stream where water temperature had increased from 2 to $18{ }^{\circ} \mathrm{C}$ that the mechanism of community assembly was typically tolerance, and that only a few taxa $(<15 \%)$ were lost, suggesting that in these kinds of systems networks will increase in both size and complexity as glacial influences wane.

In a study of biomass production in quantified stream food webs along an altitudinal gradient in the French Pyrénées, Lavandier and Décamps (1983) characterized changes in the distribution and magnitude of energy flows, together with increases in taxonomic richness, along a maximum water 
temperature gradient from 4.5 to $13{ }^{\circ} \mathrm{C}$. The larvae of small taxa (Chironomidae) were replaced as the dominant primary consumer of periphyton and detritus by larger taxa (Baetis mayflies and Allogamus auricollis caddisflies) along the thermal gradient. However, the Chironomidae still formed the major energy source for invertebrate predators across all sites, perhaps owing to their smaller body size not affording them an upper body-size refugium from gape-limited predators (cf. Woodward et al., 2005a). Such taxonomic and functional shifts in mountain stream food webs might be expected more widely across the world, owing to global reductions in glacier and snowpack extent (e.g. Brown et al., 2007; Milner et al., 2009).

Highly resolved studies of natural systems that can be used for detecting climate change impacts on ecological networks are still scarce, but several model systems, including those we identified in Section II, offer promise within this context. The biogeographical isolation of Antarctica provides a close-to-pristine environment for studying intact ecosystems (Arntz et al., 1994; Chown and Gaston, 2000; Clarke, 1983; Dayton, 1990; Gray, 2001; Hedgpeth, 1971) and the recently characterized food web of the eastern Weddell Sea shelf and slope region (Figure 9) contains 488 species and over 16,000 feeding links (Brose et al., 2005; Jacob, 2005). Many species are opportunistic trophic generalists, resulting in high omnivory and linkage density within the network (Brenner et al., 2001; Jacob et al., 2003). Rising temperatures and shifts in the position of warm and cold waters as the ice sheets melt, however, could open the door to colonization of a suite of new apex predators: invasions of shark species not previously found in the Antarctic could potentially exert powerful top-down effects upon the slowgrowing and poorly defended resident fauna in the food web (Aronson et al., 2007; Clarke et al., 2004), and this is likely to lead to extensive rewiring of the network if these species are lost (Figure 9). In addition to potential increases in the rate and number of these biological perturbations (i.e. invasions), physical disturbances are also likely to increase in the Antarctic, where icebergs are being calved from glaciers and ice sheets at an accelerating rate, which can alter large areas of benthic marine food webs by scouring the sea bed and effectively resetting the clock of food web assembly at more local scales (Teixidó et al., 2007; Figure 10).

We need a mechanistic framework that allows us to predict where a given species is likely to forge links in a given network: several approaches based on body size have been used successfully in predator-prey networks (e.g. Petchey et al., 2002), and other approaches have also been developed recently in the plant-pollinator and host-parasitoid literature. These need to be refined to account for changing environmental conditions and then tested for their ability to predict network effects of climate change. Ives and Zhu (2006)have proposed a method that could be applied to host-parasitoid webs, based on the phylogenetic structure of the network. Essentially, if the 


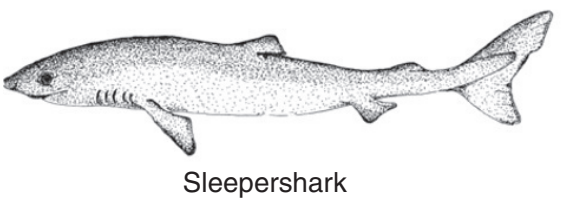

Somniosus microcephalus (a. $6.4 \mathrm{~m}$ )

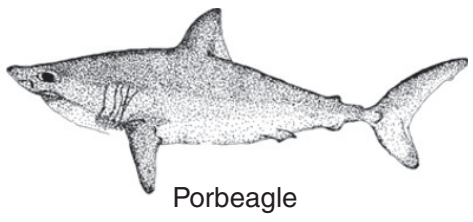

Lamna nasus (a. $2.5 \mathrm{~m}$ )
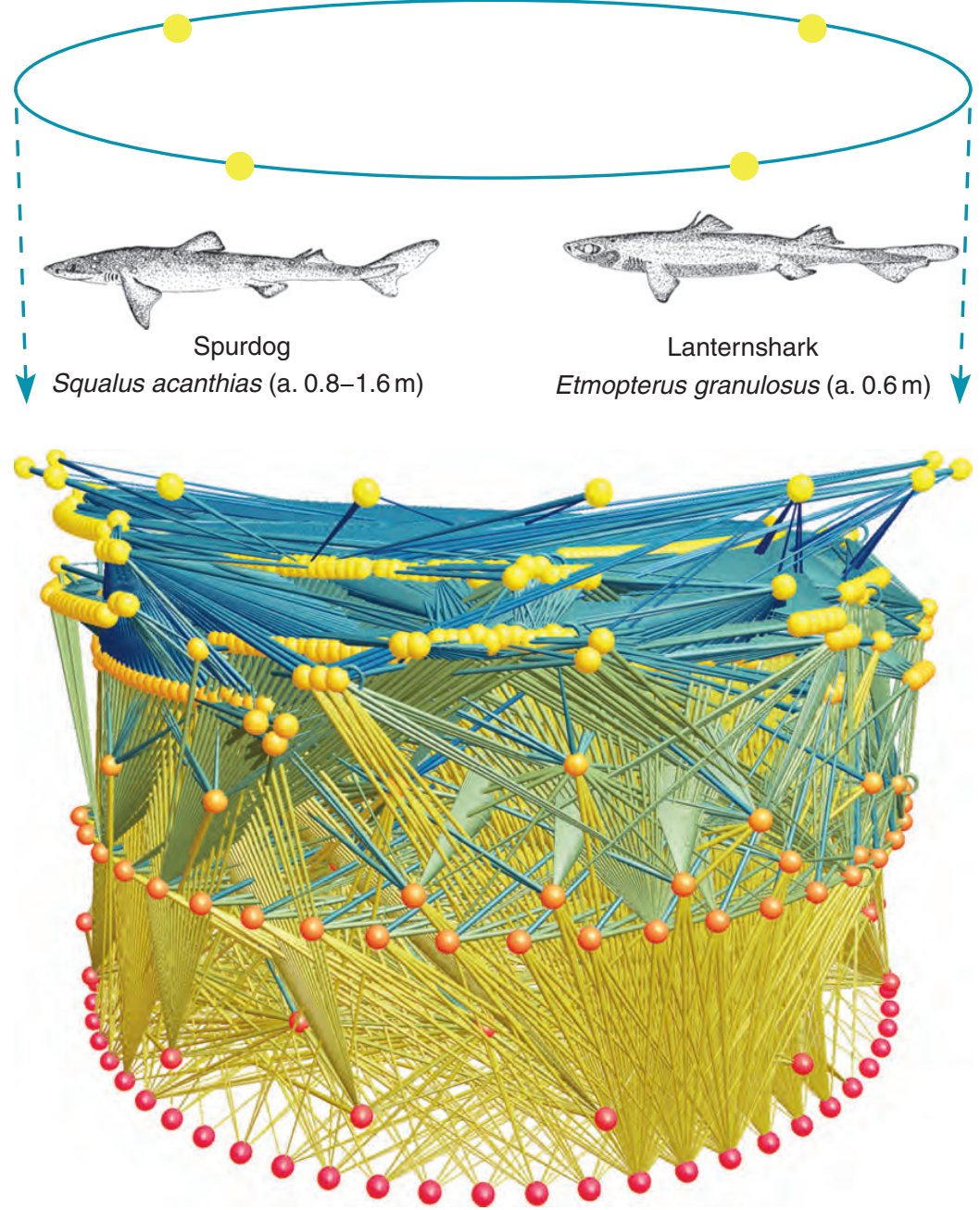

Figure 9 Directional change in the Weddell Sea food web, Antarctica. The preinvasion food web contains 492 species, 16,137 links and no 'true' top predators; the post-invasion food web contains 497 species, 16,344 links and true top predators. The post-invasion web here is a hypothetical web, constructed by simply including the sharks and links with prey items they would likely take according to expert opinion. Cascading effects including possible extinctions are not considered. 

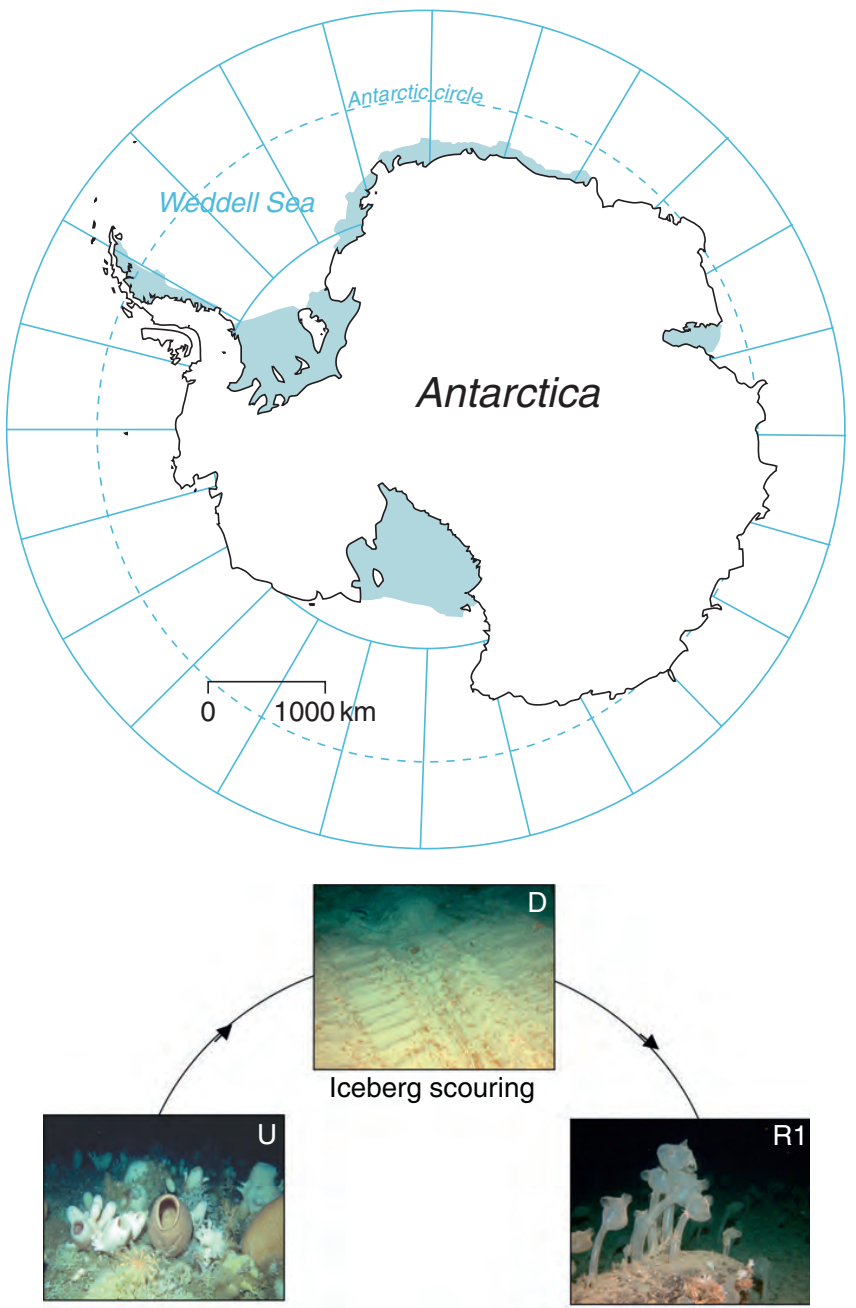

Undisturbed
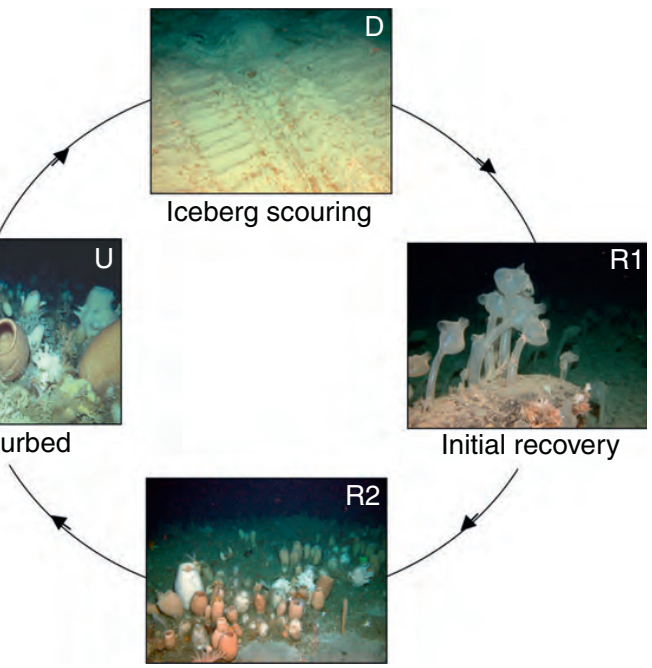

Initial recovery

Secondary recovery

Figure 10 Weddell Sea food web, Antarctica, depicting cycles of ice-scouring of the sea bed and subsequent recovery of the benthic food web. Photographs (C) supplied by Julian Gutt at the Alfred Wegener Institute for Polar and Marine Research, 27568 Bremerhaven, Germany. 
host range of a parasitoid is constrained by host phylogeny (i.e. hosts within the range are more closely related to each other than they are to hosts outside the parasitoid's range), and likewise the 'parasitoid range' of a host is constrained by parasitoid phylogeny, then it should be possible to calculate the probability that an invading species with a given phylogenetic position will interact with each of the species already in the network. Similar approaches might be usefully extended to other systems, particularly plant-pollinator networks where modular structures seem to be extremely common, and which might reflect analogous phylogenetic constraints within closely related taxa and coevolutionary links between consumers and resources (Jordano et al., 2010). Unlike food webs and host-parasitoid systems, however, the interactions within these networks are primarily mutually beneficial and also typically more temporally dynamic (at least at higher latitudes) (Olesen et al., 2010). In addition to the current range of approaches and modelling techniques used to predict network assembly, more recent work has identified a possible link between ecological stoichiometry and invasion success (González et al., 2010). This suggests another possible means to employ a first-principles approach, in line with the general aims of this chapter, as a predictive tool that could help to reduce the high levels of contingency which typify many of the current phenomenological approaches used to assess species range shifts (e.g. bioclimatic envelope models).

\section{B. Phenological Matches and Mismatches: Temporal Rewiring of Ecological Networks}

The impacts of climate change on ecological networks are likely to act via both spatial (previous section) and temporal/phenological coupling and decoupling of interactions (Winder and Schindler, 2004). Direct, specieslevel climate change effects that may precipitate phenological rewiring of networks could include decreased development time, and increased survival and a longer growing season, leading to more generations per season. These changes may also impact population dynamics, as observed for Arctic insect herbivores (Strathdee et al., 1993). Changes in generation time may be relatively slow to respond to a changing climate (Hulle et al., 2008), especially if photoperiod (which is independent of climate change), rather than temperature, is a key driver of life-history events (such as diapause and reproduction). The important role of phenology, that is the timing of key life history events, in ecological communities was recognized many decades ago by Charles Elton, who devoted an entire chapter to 'Time and animal communities' in his influential book Animal Ecology (1927). He wrote: 'Many of the animals in a community never meet owing to the fact that they become active at different times' (p. 83). In modern ecological parlance, Elton was 
highlighting the important role of phenology in controlling the links that are realized in ecological networks (cf. Durant et al., 2007). The so-called match/ mismatch hypothesis, a term first coined by Cushing (1975), originally focused on the extent of coincidence between the time of hatching of fish larvae and the time when their planktonic prey become available. This was later extended by Pope et al. (1994), who discussed how larval and juvenile fishes needed to 'ride' the seasonal wave of plankton production to grow and survive: if the phenology of consumers and resources becomes decoupled due to differential responses (which again, may be related to correlates between body size, individual metabolism, and life history and developmental rates), this could break or weaken many of the key links, especially those at the base of the food web.

In host-parasitoid and other insect-dominated networks in temperate zones, for example insects enter an overwintering state, either as eggs, larvae, pupae or adults, depending on the taxon. The effects of warming could simply result in all insects becoming active earlier in the season to the same degree (e.g. Harper and Peckarsky, 2006), but there is also evidence that increasing day length, which is independent of climate change, plays an important role for some taxa. This could lead to a mismatch in early season emergence of species that rely differently on light versus temperature cues, with powerful repercussions for community dynamics, due partly to priority effects. For example an early emerging aphid species can support a population of a parasitoid that prevents the establishment of a later-arriving aphid species through apparent competition, while synchronized arrival leads to exclusion of the former aphid and the parasitoid, due to resource competition and unstable dynamics, respectively (Jones et al., 2009). Although it is currently difficult to make general predictions about these kinds of effect, given the limited availability of suitable data, it is likely that the relative importance of day length and temperature for different taxa depends on the developmental stage in which they overwinter. It seems reasonable to suggest that species that overwinter as adults might simply need to reach a minimum temperature for activity to commence, whereas those that overwinter as pupae, for example may need external cues such as day length to trigger the onset or completion of metamorphosis. If this is the case, it gives us some identifiable species traits that could potentially be used in future work to formulate more general theories and to improve our ability to predict how and when phenological decoupling might arise within certain types of ecological networks.

Within most ecological networks, a large proportion of possible links remain unobserved. Some of these are missing from available data because of insufficient sampling, as revealed by yield-effort curves (e.g. Ings et al., 2009; Woodward et al., 2005a), whereas others are truly absent in nature and will not be observed, irrespective of sampling effort (Jordano et al., 2003; Olesen et al., 2010). Truly absent links are accounted for by biological 
Zackenberg, NE Greenland $74^{\circ} \mathrm{N}$, tundra phenology change in days from 1996 to 2005

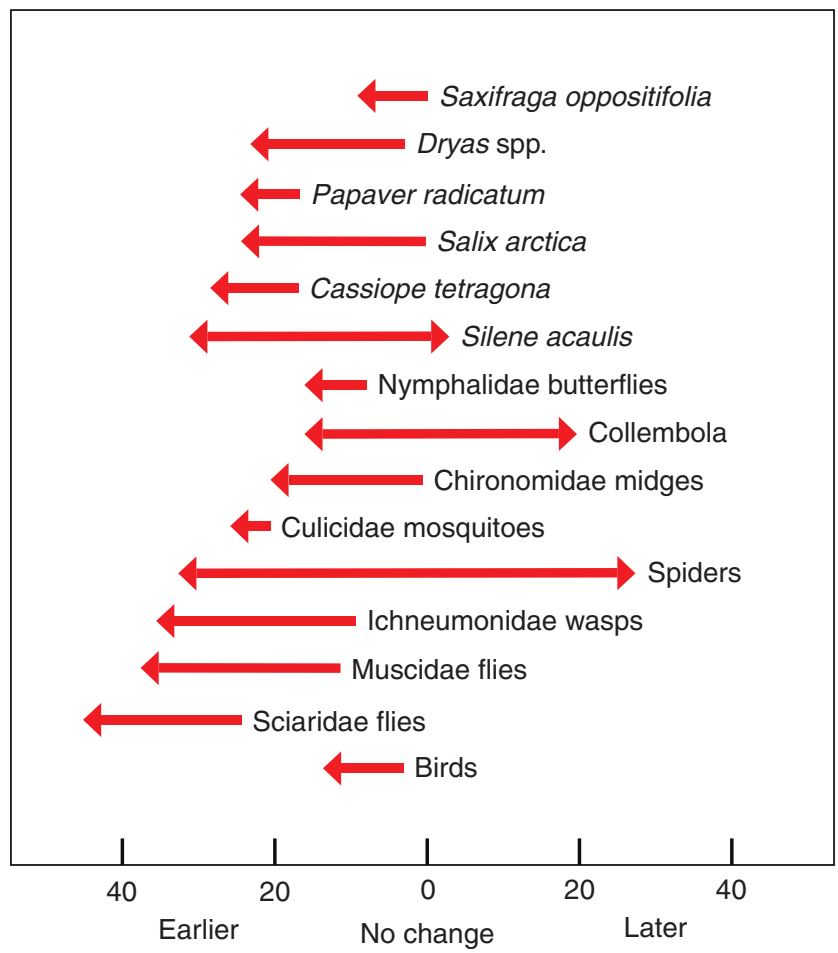

Figure 11 Phenological matches and mismatches in plant-pollinator networks in Greenland (after Olesen et al., 2008). See also Olesen et al. (2010) for further details of the study system and network properties.

phenomena, including phenological and spatial uncoupling, size- or rewardmismatching and foraging constraints (Jordano, 1987; Jordano et al., 2006; Nilsson, 1988; Olesen et al., 2008). Phenological uncoupling (Figure 11) occurs when the phenophases (activity periods) of species in a network do not overlap (Cushing, 1975; Jordano, 1987), and such overlaps often have to be substantial for links to be both manifested and detected by an observer (Jordano, 1987).

Olesen et al. (2010) have demonstrated the importance of phenological uncoupling (weak or no overlap in phenophases) in a Greenland pollination network from the high Arctic $\left(74^{\circ} 30^{\prime} \mathrm{N}, 21^{\circ} 00^{\prime} \mathrm{W}\right)$, where connectance was only $15 \%$, that is the proportion of unobserved potential links was $85 \%$. They found that phenological uncoupling accounted for nearly one-third of all unobserved links in this network. However, the importance of phenological uncoupling varies among networks and is likely to be more extreme at the edge of species ranges and at high latitudes, due to a severely constrained 
growing season, whereas it may be insignificant where one or both of the interacting entities are perennial. Examples of the latter scenario include the tropical Trinidad hummingbird-plant network studied by Snow and Snow (1972), where resident hummingbirds harvest nectar all year round, and tropical domatia ant-plant networks (Fonseca and Ganade, 1996), where both mutualists are intimately linked to each other for extended periods.

There is increasing evidence that significant changes in the phenology of plants and animals have occurred in response to recent climatic changes (Forrest et al., 2010) and uncoupling has now been documented in a number of systems (herbivorous insects/insectivorous birds/raptors: Both et al., 2009; Thackeray et al., 2010), highlighting potential for climate-driven reshuffling of phenologies to alter network structure and dynamics dramatically (e.g. Hegland et al., 2009; Høye et al., 2007; Inouye, 2008; Inouye et al., 2003; Memmott et al., 2007; Tylianakis et al., 2008). A recent review of phenological change in terrestrial and aquatic systems in the UK has highlighted that higher trophic levels (i.e. secondary consumers) are slower to respond to climatic changes than are the lower trophic levels, making the former especially vulnerable to phenological uncoupling (Thackaray et al., 2010).

Additional challenges to predicting responses to climatic change arise if the onset and length of phenophase are species specific (Høye et al., 2007). Further, differential responses may even occur among populations of the same species: for example phenological uncoupling has been reported for great tits and the winter moth larvae they feed their young on in Denmark (Visser et al., 2009), whereas another population in the UK has been able to match the earlier emergence of winter moth caterpillars (Charmantier et al., 2008). These differences are likely to reflect both genetic variation and phenotypic plasticity.

Because species responses are embedded within the wider network, the latter's degree of modularity or compartmentalization has important consequences for phenological matches/mismatches (Olesen et al., 2010). Large mutualistic networks are typically nested, modular and hierarchical, with a dense core of links shared by small club of generalists connected by two tails to a swarm of specialists. Consequently, the latter may have their relatively short phenophase displaced considerably before they become uncoupled from their generalized linkage partner (Olesen et al., 2010). The hierarchical nature of these nested link patterns adds a strong element of robustness against perturbations and helps to facilitate species coexistence, at least in mutualistic networks: most species in modules are short-lived specialists linked to local module hubs of intermediate lifespan, which are further linked to network hubs of greater longevity (Olesen et al., 2010). Consequently, the importance of phenophase displacement among specialists can be mitigated by module hubs, and displacement among these may be buffered by network hubs, such that nestedness and modularity can counteract the effects of phenophase disturbance. Climate change could potentially trigger extinction vortices within mutualistic networks: for instance, as a species becomes rarer 
its population phenophase shortens, which increases the chances of it becoming phenologically uncoupled from its resources, which in turn can reduce mean fitness and abundance, and so on. However, phenological coupling/ uncoupling appears to be a gradual phenomenon, and Olesen et al. (unpublished data) have shown that many unobserved links in a network may be due to limited temporal overlap, which needs to be substantial to achieve a high linkage probability (Olesen et al., 2010).

Whilst these models give invaluable insights into the importance of phenological constraints in plant-pollinator networks, they do have limitations. In particular, they still lack a general mechanistic basis, and thus predictive power, and they have to rely upon making fundamental assumptions about pollinator responses to global warming due to the current lack of data. It is therefore vital that future studies begin to characterize species responses to elevated temperature directly (e.g. see studies on causal effects of temperature on bird reproduction; Visser et al., 2009), and also to test more rigorously for presence of easily measured traits (e.g. body size) that could improve our ability to generalize. Within food webs, there are suggestions, for instance that the extent of phenological uncoupling varies with trophic status and/or body size, with faster responses occurring among smaller organism lower in the web, which can release them from top-down control as their more slowly responding consumers become progressively shifted out of phase (e.g. Thackeray et al., 2010; Winder and Schindler, 2004). There is also evidence that community assembly over biogeographic scales is related to food web structure, in a seemingly analogous manner to that observed in mutualistic networks, with webs initially being composed of a core of a few trophic generalist species to which more specialist taxa attach themselves progressively over time (Piechnik et al., 2008).

Although many of the studies highlighted earlier have demonstrated the importance of phenological change in ecological networks, a more mechanistic viewpoint is needed to begin to predict the potential impacts of climate change on ecological networks through phenological coupling/uncoupling. Detailed phenophase data will become essential baseline information for future studies estimating climate effects on network structure, especially in Arctic networks, where climate changes are most marked (e.g. Witze, 2008). High-quality phenophase data are available for some network types, and models incorporating such data have suggested that plant-pollinator interactions are likely to be severely disrupted, with consumers potentially encountering periods without food and plants encountering periods without pollinators (Memmott et al., 2007). The development of this understanding is currently hindered by the population level focus of most phenophase research to date (i.e. from when the first individual in a population initiates its activity until the last ceases). By implication, more abundant species are likely to have a longer population-level phenophase at a given site, but from a network perspective, interactions between individuals are crucial, so in future 
we will need to shift our focus to consider changes in individual phenophase, or at least mean individual phenophase (Olesen et al., 2010).

\section{MULTIPLE AND INTERACTING COMPONENTS OF CLIMATE CHANGE}

So far, we have subdivided climate change into several seemingly neatly delimited components (e.g. changes in environmental temperature, atmospheric composition and fluid viscosity). In reality, though, many of these will be occurring simultaneously, and may act additively or synergistically (e.g. Feuchtmayr et al., 2009; Moss et al., 2003). Synergies, which might either exacerbate or ameliorate the overall effects of climate change, have been largely overlooked from a network-level perspective. In this final section, we will consider how the components of climate change combine, in terms of their impacts on the higher levels of biological organization, in either an additive or synergistic manner.

\section{A. Combined Impacts of Warming and Atmospheric Change on Metabolism and Stoichiometry Within Ecological Networks}

Metabolic theory and ecological stoichiometry provide a useful roadmap for accomplishing the task of assessing the combined effects of two of the most obvious aspects of climate change, warming and elevated $\mathrm{CO}_{2}$ levels in the environment, because they draw clear linkages between easily measured characteristics (e.g. body size, temperature) and higher level ecological dynamics (e.g. metabolism, population growth, energy and material flux). Moreover, these unifying frameworks are rooted in first principles of thermodynamics and mass conservation and can be applied across multiple levels of organization, from individuals to whole ecosystems (Brown et al., 2004; Sterner and Elser, 2002).

Metabolism and rates of ecological processes are clearly inseparable from the stoichiometric requirements of organisms for biologically important elements such as nitrogen $(\mathrm{N})$ and phosphorus $(\mathrm{P})$, and these may differ markedly between consumers and resources within a network (Allen and Gillooly, 2009; Gillooly et al., 2005; Reich and Oleksyn, 2004; Sterner and Elser, 2002). For instance, N:P ratios of marine primary producers increase with ambient temperature, whereas this does not seem to be the case for animals, which show a virtually negligible response (Figure 12). Building new biomass and maintaining elemental homeostasis (as in the case of consumers) necessitate the uptake or assimilation of $\mathrm{N}$ or $\mathrm{P}$ in some proportion to the amount of carbon fixed or assimilated. Although metabolic theory may 
A

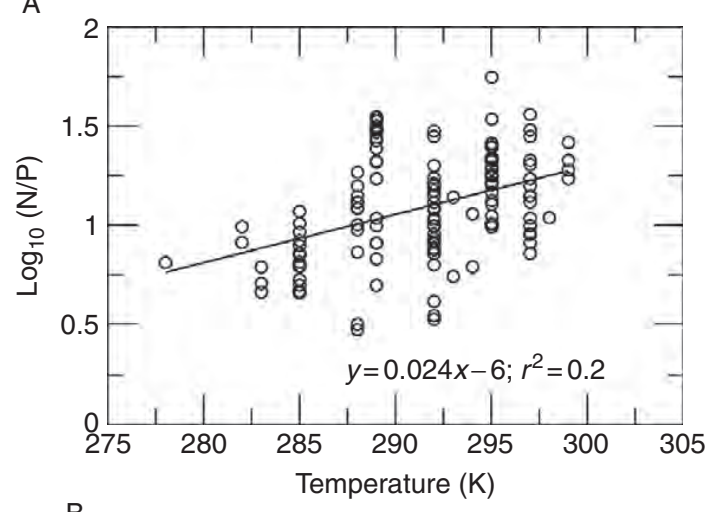

B

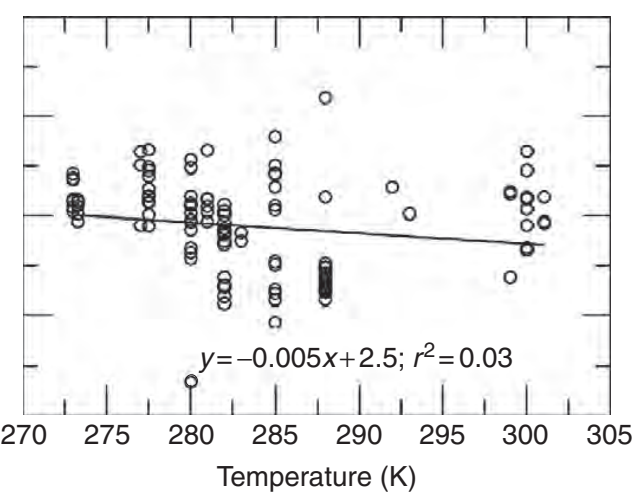

Figure 12 The effects of temperature on NP ratios in marine autotrophs (A) and heterotrophs (B). Data are redrawn from Brey et al. (2010). Notice that the Log10 (NP) of autotrophs is strongly, positively related to the mean annual temperature (K) of the organisms environment, while the $\log 10$ (NP) of heterotrophs is relatively independent of environmental temperature. These patterns likely reflect the relative stoichiometric plasticity of autotrophs relative to the homeostatic nature of heterotrophs. However, a mechanistic explanation for the apparent increase in plant NP with increasing temperature is currently lacking in the literature.

explain significant variability in metabolism and energy flux across broad ranges in temperature and body size, important additional variation may be related to resource stoichiometry (Brown et al., 2004; Jeyasingh, 2007; Sterner, 2004; Sweeney et al., 1986). Thus, theoretical and empirical advances that combine metabolic and stoichiometric approaches should strongly improve our ability scale-up lower level effects to predict interactive effects of climate change on food webs and ecosystems (Allen and Gillooly, 2009).

For many ecosystems, the components needed to develop a systematic approach to understanding these additive or interactive effects of environmental warming and changes in $\mathrm{CO}_{2}$ concentrations may already be available to a large extent but have not yet been integrated into a network-level perspective. Studies into the interacting effects of the different components of climate 
change on the growth of primary producers at the base of the network provide a useful starting point for gauging the potential joint effects of elevated $\mathrm{CO}_{2}$ and temperature, especially in aquatic systems, for which both theory and experimental evidence are better developed. For instance, phytoplankton growth physiology has been extensively studied using chemostats and modelled using a range of generalizations (e.g. Klausmeier et al., 2004a,b; Litchman et al., 2004; White and Zhao, 2009) of the classic Droop model (Droop, 1983) of nutrient uptake and growth. Importantly, parameters of this model and its variants are related to body size (Litchman et al., 2007, 2009) and temperature (Aksnes and Egge, 1991; Geider et al., 1998). The influence of the availability of multiple nutrients has also been extensively modelled and examined experimentally (e.g. Geider et al., 1998; Urabe and Sterner, 1996). Recent work has used allometric parameterization of models to show quantitatively that the optimal size of competing phytoplankton cells increases with the typical period between nutrient upwelling events (Litchman et al., 2007, 2009), and a similar approach could clearly be used to model the separate and combined effects of increased temperature and $\mathrm{CO}_{2}$ on this competitive balance.

In a study of lake plankton, Hessen et al. (2004) showed algal C:P ratios were significantly higher in summer than in winter, which they attributed to seasonal shifts in the thermal stimulation of photosynthesis. Both temperature and $\mathrm{CO}_{2}$ concentrations affect autotroph stoichiometry in ways that can ramify through the food web, and theory suggests a competitive tradeoff exists between growth and nutrient storage in phytoplankton along an axis of individual body size. Essentially, larger phytoplankton can store nutrients to survive periods of resource limitation, whereas smaller phytoplankton can grow faster when nutrients are abundant; however, if $\mathrm{CO}_{2}$ uptake is diffusion-limited larger cells should be favoured as concentrations rise (Aksnes and Egge, 1991; Finkel et al., 2010; Litchman et al., 2009). This raises the intriguing suggestion that elevated $\mathrm{CO}_{2}$ levels and rising temperatures might have opposite (i.e. synergistic) effects on body size. Since temperature affects rates of both nutrient uptake (Aksnes and Egge, 1991) and growth (Geider et al., 1998), it should alter this competitive balance, potentially changing the size structure of marine phytoplankton assemblages at the base of the food web. Stratification within the water column of many lakes and oceans is also likely to increase as temperatures rise (unless mitigated by increased mixing due to more intense storm events), reducing availability of limiting nutrients (i.e. low N:P ratios) to phytoplankton in the photic zone (Richardson and Schoeman, 2004; Winder et al., 2009). In addition to the potential impacts on size-selective herbivores, changes in phytoplankton body size will alter the rate of sinking through pycnoclines, which has additional implications for encounter rates with zooplankton at the next trophic level, and hence the rates and magnitude of energy transfer and nutrient cycling with the food web. If, for instance, temperature, rather than $\mathrm{CO}_{2}$ availability, is the primary driver, smaller phytoplankton should 
be favoured, and there is some evidence to suggest that this might be the case (e.g. Moran et al., 2010).

One exciting avenue towards blending metabolic and stoichiometric approaches that has great potential for predicting climate change effects on ecological networks is the application of threshold elemental ratio (TER) models (Frost et al., 2006; Sterner, 1997; Sterner and Hessen, 1994). These incorporate information about consumer elemental composition (CNP ratios) and physiology (assimilation efficiencies, respiration) to quantify the resource elemental ratios at which the consumer switches from limitation by one element (e.g. C) to another (e.g. P; Frost et al., 2006). In addition, these models provide quantitative estimates of consumer-resource elemental imbalances, which have the potential to influence community assembly, material flux in food webs and interaction strengths. Such models can be easily modified to incorporate changes in temperature (via effects on individual respiration or ingestion; Frost and Elser, 2002) or food quality (via effects on CNP ratios of prey items), and, when applied to entire food webs, may provide a powerful tool for predicting climate-induced shifts in food web structure and dynamics.

The TER approach incorporates important stoichiometric differences between autotrophs and heterotrophs that may lead to contrasting responses to climate warming and emergent effects on network patterns and processes (Sterner and Elser, 2002). For example autotrophs show considerable variation in C:nutrient ratios (even within a single species) and can vary strongly with regard to their nutrient-use efficiencies (Cross et al., 2005; Rhee and Gotham, 1981; Sterner et al., 1997; Vitousek, 1982). This flexibility means that a broad range of carbon fixation rates can be maintained with the same rate of nutrient supply. Thus, holding nutrient concentrations constant, both autotrophic production and C:nutrient ratios should increase with warming.

In contrast to autotrophs, elemental stoichiometry of heterotrophic consumers is relatively fixed or homeostatic (Elser et al., 2000; Frost et al., 2003, but see Cross et al., 2003; Demott et al., 2001). Although consumer metabolic rate should respond positively to increases in temperature (Gillooly et al., 2001), this increased metabolism must be matched with increased assimilation of nutrients to maintain positive growth or homeostasis (Frost et al., 2005). In the short term, a combination of flexible (and increasing) autotroph $\mathrm{C}$ :nutrient ratios and fixed consumer C:nutrient ratios should result in elevated elemental imbalances with increased temperature. Despite immediate increases in consumer metabolic rates, these increased imbalances should negatively affect growth and production of consumers, particularly those taxa with high nutrient requirements and low TERs (Figure 13).

Long-term food web responses to elevated temperature should, however, be fundamentally different because of time lags between short-term physiological responses of individual taxa and taxonomic shifts in the community. Over these longer time scales, elevated temperatures and low nutrient availability (Figure 13) should select for consumers with relatively low nutrient requirements (Frost et al., 2006), high body C:nutrient ratios (Woods et al., 


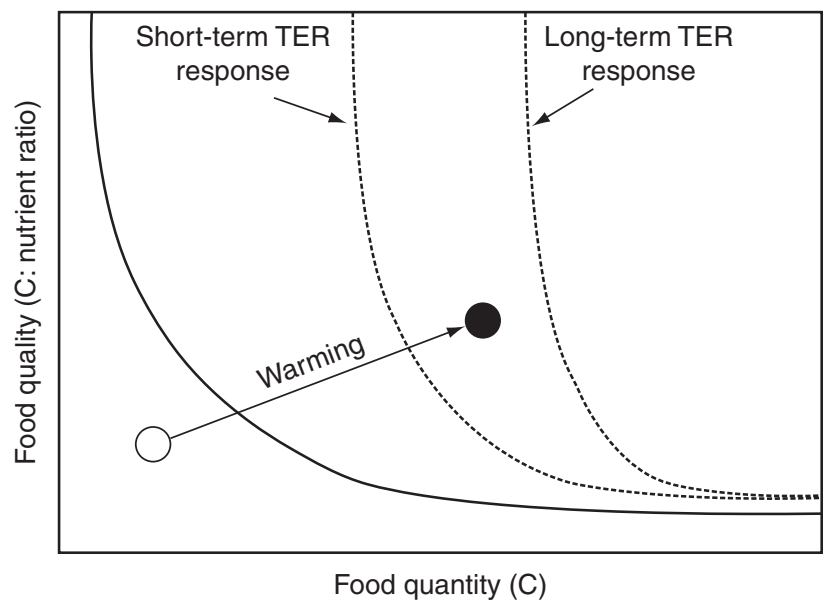

Figure 13 Predicted changes in food quantity and quality with increased temperature (from open circle in cold streams to filled circle in warm streams) and consumer threshold elemental ratio isoclines (TERs; solid, dashed, and dotted lines). Both food quantity and C:nutrient ratios are predicted to increase with warming. The solid line represents the TER of cold-adapted taxa in cold streams. If the combination of food quantity and quality falls below this line (as in the open circle), the consumer is predicted to be quantity (or C) limited. In contrast, if the combination of food quantity and quality falls above this line, the consumer is predicted to be nutrient limited (Sterner, 1997). The dashed line represents short- to mid-term response of the TER of this taxon in warm streams; the shift in TER is due to increased consumer respiration at higher temperatures (Frost and Elser, 2002). In this case, declines in food quality (increased C:nutrient ratios) and shifts in TER (driven by increased consumer respiration at higher temperatures) lead to nutrient limitation of consumer production and reduced flows of carbon and nutrients through this consumer. The dotted line represents predicted TER isoclines of consumers in temperature-acclimated communities (i.e. long-term evolutionary responses or shifts in community structure). Taxa in these communities are predicted to have high TERs and consequently should not experience warming-induced nutrient limitation.

2003) and high TERs. These warming-induced shifts in food web structure and stoichiometry should therefore alter the identity of the nodes (i.e. species turnover and/or altered size-classes), as well as the strength of interactions and the rates of elemental fluxes within trophic networks.

Although use of TER models is still in its infancy (i.e. most studies have focused on single consumer-resource interactions; Anderson and Hessen, 2005; Frost and Elser, 2002), there is great potential for expansion to examine the dynamics of whole food webs. Importantly, recent theoretical advances (Allen and Gillooly, 2009; Gillooly et al., 2005) that integrate metabolic theory and ecological stoichiometry should aid in application of this approach to the study of complex food webs. For example Allen and Gillooly (2009) derived an elegant model that predicts TERs based on the densities and individual mass of fundamental metabolic units (e.g. protein 
complexes) and organelles (e.g. ribosomes and mitochondria) responsible for metabolism, which scale predictably with body size and temperature. These authors demonstrated a reasonable fit between their theoretically based TERs and those parameterized from literature values (Frost et al., 2006) for $>30$ aquatic animal taxa spanning a broad array of body size and phylogenetic history. These results are encouraging and suggest that scaling theory may indeed help guide predictions about food web responses to climate change. Nonetheless, as we progress towards using these models, more rigorous validation against empirical food web data will be essential.

\section{B. Other Additive and Synergistic Effects of the Components of Climate Change}

The potential synergies among the components of climate change other than temperature and elevated $\mathrm{CO}_{2}$ are currently far less well known. For instance, although a few studies have highlighted the potential for viscosityderived effects in ecological networks, little is known about their importance relative to other temperature-dependent mechanisms (e.g. metabolic rates). The metabolic costs of predator-induced phenotypic defences, which are prevalent in many zooplankters, may, for instance be determined by viscosity, which might account for their reduced expression at lower temperatures (Lagergren et al., 2000). Whilst we have quantitative evidence for the importance of temperature-dependent viscosity for individual responses that affect encounter and ingestion rates (e.g. via altered swimming speed and feeding rates), our understanding of the implications for population and community dynamics is still in its infancy.

Given the potential for a complex array of synergies between the different components of climate change to affect ecological networks, a key priority is to distinguish the likely main effects and interactions from those that are subsidiary or trivial. The powerful overarching effects across multiple levels of organization (Brown et al., 2004) of body size and temperature (and their combined effect on metabolism) are strong contenders for being principal drivers. As such, the temperature-metabolism relationship might be viewed as the first axis of interest, with others representing the residual variation about the line. Similarly, body size has well-known effects on individual foraging behaviour, such as allometric relationships with handling time and attack rates (Petchey et al., 2002). Thus, quantifying body sizes of consumers and resources (and recording the environmental temperature) should capture a relatively large portion of the relevant characteristics of an ecological network. It is encouraging that this appears to the case for the small but increasing number of food webs that have been described in this way (e.g. Jonsson et al., 2005; Layer et al., 2010b; McLaughlin et al., 2010; Mulder and Elser, 2009; O'Gorman and Emmerson, 2010; Petchey et al., 2002; Woodward et al., 2005a), but more data are still needed before we can make robust generalizations. 
Among the subsidiary (but potentially interacting) axes, stoichiometric constraints may well be the next major determinant of the strength of interactions in many ecological networks, at least between the basal resources and the primary consumers that represent the first links in the food chain (e.g. Jeyasingh, 2007). The outline of a predictive framework for gauging likely responses of ecological networks to climate change, based upon well-described and relatively simple relationships related to metabolic scaling, foraging theory, and ecological stoichiometry, seems to be edging slowly towards being within our grasp (e.g. Petchey et al., 2010). This general framework could then be overlain with the seemingly more contingent effects of species-specific bioclimatic envelopes, phenological effects and community assembly/disassembly models. Indeed, some recent studies have started to forge links from first principles to these higher-level responses, such as the posited relationship between ecological stoichiometry and invasion success (i.e. chemical-metabolic constraints on network assembly) suggested by González et al. (2010).

\section{CONCLUSIONS}

One of the key challenges for predicting effects of climate change on ecological networks is developing theory that explicitly incorporates both the separate components of climate change and their potential interactions among them (e.g. increased temperature $\times$ atmospheric $\mathrm{CO}_{2}$ ). In an ideal world, ecological networks would be constructed from individual-based data, with directly observed nodes and links, over multiple generations, and at spatial and temporal scales that capture the essential properties of the study system, because this provides the most relevant and reliable data with which to assess the likely responses of these complex systems to climate change. Further, the relevant components of climate change under investigation should be imposed on the system as dynamic stressors, to identify causal relationships and to differentiate between potentially transient and equilibrial responses. Once these criteria have been met, a range of more specific hypotheses can be tested rigorously within a general predictive framework. Of course, in reality compromises must be made, but even if these goals are only partially met we will be better able to develop a more coherent and less contingent view of how Earth's ecosystems might respond to climate change. Given that one commonly recurring theme is that larger organisms seem to be those most adversely affected by many of the components of climate change (e.g. Jeppesen et al., 2003; Meerhoff et al., 2007; Moran et al., 2010), and that metabolic and stoichiometric constraints underpin so many key ecological processes, focusing on these drivers and responses seems to be an obvious place to start developing the network-level perspective we need to help predict the impacts of future climate change. In particular, we need to start 
constructing, monitoring and manipulating networks from as wide a range of natural systems as possible over extended time frames, and across multiple levels of organization. Disentangling the responses to climate signals in natural multi-species systems is a major challenge that will require considerable logistic commitments on a truly global scale and over many years, but initiating such research at this still early stage will undoubtedly prove invaluable for developing our predictive capacity in the near future, as our climate continues to change apace.

\section{ACKNOWLEDGEMENTS}

We would like to thank Stephanie Parker and Alex Huryn for providing additional food web data, Haley Cohen, Graham Wall, Gisli Gislason and Jon Olafsson for assistance with sample collection for the Icelandic food webs, and Sarah Pottinger and Jacques Deere for helping to organize the workshops. Network images were produced with FoodWeb3D, written by R.J. Williams and provided by the Pacific Ecoinformatics and Computational Ecology Lab (www.foodwebs.org, Yoon et al., 2004). This project was supported by a Natural Environment Research Council Centre for Population Biology grant awarded to G.W.

\section{REFERENCES}

Abrusàn, G. (2004). Filamentous cyanobacteria, temperature and Daphnia growth: The role of fluid mechanics. Oecologia 141, 395-401.

Aksnes, D.L., and Egge, J.K. (1991). A theoretical model for nutrient uptake in phytoplankton. Mar. Ecol. Prog. Ser. Oldendorf 70, 65-72.

Allen, A.P., and Gillooly, J.F. (2009). Towards an integration of ecological stoichiometry and the metabolic theory of ecology to better understand nutrient cycling. Ecol. Lett. 12, 369-384.

Allen, A.P., Gillooly, J.F., and Brown, J.H. (2005). Linking the global carbon cycle to individual metabolism. Funct. Ecol. 19, 202-213.

Anderson, T.R., and Hessen, D.O. (2005). Threshold elemental ratios for carbon versus phosphorus limitation in Daphnia. Freshw. Biol. 50, 2063-2075.

Arntz, W.E., Brey, T., and Gallardo, V.A. (1994). Antarctic marine zoobenthos. Oceanogr. Mar. Biol. Annu. Rev. 32, 241-304.

Aronson, R.B., Thatje, S., Clarke, A., Peck, L.S., Blake, D.B., Wilga, C.D., and Seibel, B.A. (2007). Climate change and the invasibility of the Antarctic benthos. Annu. Rev. Ecol. Evol. Syst. 38, 129-154.

Atkinson, D. (1994). Temperature and organism size-A biological law for ectotherms. Adv. Ecol. Res. 25, 1-58.

Atkinson, D., Ciotti, B.J., and Montagnes, D.J.S. (2003). Protists decrease in size linearly with temperature: ca. $2.5 \%$ C-1. Philos. Trans. R. Soc. Lond. B 270, 2605-2611.

Badger, M.R., Andrews, T.J., Whitney, S.M., Ludwig, M., Yellowlees, D.C., Leggat, W., and Price, G.D. (1998). The diversity and coevolution of Rubisco, plastids, pyrenoids, and chloroplast-based $\mathrm{CO} 2$-concentrating mechanisms in algae. Can. J. Bot.-Rev. Can. Bot. 76, 1052-1071. 
Barnes, D.K.A., Verling, E., Crook, A., Davidson, I., and O'Mahoney, M. (2002). Local population disappearance follows (20 yr after) cycle collapse in a pivotal ecological species. Mar. Ecol. Prog. Ser. 226, 311-313.

Barnes, C., Bethea, D.M., Brodeur, R.D., Spitz, J., Ridoux, V., Pusineri, C., Chase, B.C., Hunsicker, M.E., Juanes, F., Kellermann, A., Lancaster, J., Ménard, F., et al. (2008). Predator and body sizes in marine food webs. Ecology 89, 881.

Barnes, C., Maxwell, D.L., Reuman, D.C., and Jennings, S. (2010). Global patterns in predator-prey size relationships reveal size-dependency of trophic transfer efficiency. Ecology 91, 222-232.

Barnett, T.P., Adam, J.C., and Lettenmaier, D.P. (2005). Potential impacts of a warming climate on water availability in snow-dominated regions. Nature 438, 303-309.

Bascompte, J., and Stouffer, D.B. (2009). The assembly and disassembly of ecological networks. Philos. Trans. R. Soc. Lond. B 364, 1781-1787.

Battarbee, R.W. (2000). Palaeolimnological approaches to climate change, with special regard to the biological record. Quatern. Sci. Rev. 19, 107-124.

Beckerman, A.P., Petchey, O.L., and Warren, P.H. (2006). Foraging biology predicts food web complexity. Proc. Natl. Acad. Sci. USA 103, 13745-13749.

Berlow, E.A., Dunne, J.A., Martinez, N.D., Starke, P.B., Williams, R.J., and Brose, U. (2009). Simple prediction of interaction strengths in complex food webs. Proc. Natl. Acad. Sci. USA 106, 187-191.

Beveridge, O.S., Humphries, S., and Petchey, O.L. (2010). The interacting effects of temperature and food chain length on trophic abundance and ecosystem function. J. Anim. Ecol. 79, 693-700.

Beverton, R.J.H., and Holt, S.J. (1959). A review of the lifespans and mortality rates of fish in nature, and their relation to growth and other physiological characteristics. CIBA Found. Symp, Lifespan Animals 5, 142-177.

Bolton, T.F., and Havenhand, J.N. (1998). Physiological versus viscosity-induced effects of an acute reduction in water temperature on microsphere ingestion by trochophore larvae of the serpulid polychaete Galeolaria caespitose. J. Plankton Res. 20, 2153-2164.

Bolton, T.F., and Havenhand, J.N. (2005). Physiological acclimation to decreased water temperature and the relative importance of water viscosity in determining the feeding performance of larvae of a serpulid polychaete. J. Plankton Res. 27, 875-879.

Bonsall, M.B., and Hassell, M.P. (1998). Population dynamics of apparent competition in a host-parasitoid assemblage. J. Anim. Ecol. 67, 918-929.

Borrell, B.J. (2006). Mechanics of nectar-feeding in the orchid bee Euglossa imperialis: Pressure, viscosity and flow. J. Exp. Biol. 209, 4901-4907.

Both, C., van Asch, M., Bijlsma, R.G., van den Burg, A.B., and Visser, M.E. (2009). Climate change and unequal phenological changes across four trophic levels: Constraints or adaptations? J. Anim. Ecol. 78, 73-83.

Boudreau, P.R., and Dickie, L.M. (1992). Biomass spectra of aquatic ecosystems in relation to fisheries yield. Can. J. Fish. Aquat. Sci. 49, 1528-1538.

Boulton, A.J. (2003). Parallels and contrasts in the effects of drought on stream macroinvertebrate assemblages. Freshw. Biol. 48, 1173-1185.

Brenner, M., Buck, B.H., Cordes, S., Dietrich, L., Jacob, U., Mintenbeck, K., Schröder, A., Brey, T., Knust, R., and Arntz, W. (2001). The role of iceberg scours in niche separation within the Antarctic fish genus Trematomus. Polar Biol. 24, 502-507. 
Brey, T. (2010). An empirical model for estimating aquatic invertebrate respiration. Methods Ecol. Evol. 92-101.

Brooks, S.J., and Birks, H.J.B. (2004). The dynamics of Chironomidae (Insecta: Diptera) assemblages in response to environmental during the past 700 years on Svalbard. J. Paleolimnol. 31, 483-498.

Brose, U., Cushing, L., Banasek-Richter, C., Berlow, E., Bersier, L.F., Blanchard, J.L., Brey, T., Carpenter, S.R., Cattin-Blandenier, M.F., Cohen, J.E., Dell, T., Edwards, F., et al. (2005). Empirical consumer-resource body size ratios. Ecology 86, 2545.

Brown, J.H., Gillooly, J.F., Allen, A.P., Savage, V.M., and West, G.B. (2004). Toward a metabolic theory of ecology. Ecology 85, 1771-1789.

Brown, L.E., Hannah, D.M., and Milner, A.M. (2007). Vulnerability of alpine stream biodiversity to shrinking glaciers and snowpacks. Global Change Biol. 13, 958-966.

Burgmer, T., Hillebrand, H., and Pfenninger, M. (2007). Effects of climate-driven temperature changes on the diversity of freshwater macroinvertebrates. Oecologia 151, 93-100.

Bystrom, P., Andersson, J., Kiessling, A., and Eriksson, L.O. (2006). Size and temperature dependent foraging capacities and metabolism: Consequences for winter starvation mortality in fish. Oikos 115, 43-52.

Castella, E., Adalsteinsson, H., Brittain, J.E., Gislason, G.M., Lehmann, A., Lencioni, V., Lods-Crozet, B., Maiolini, B., Milner, A.M., Olafsson, J.S., Saltveit, S.J., and Snook, D.L. (2001). Macrobenthic invertebrate richness and composition along a latitudinal gradient of European glacier-fed streams. Freshw. Biol. 46, 1811-1831.

Charmantier, A., McCleery, R.H., Cole, L.R., Perrins, C., Kruuk, L.E.B., and Sheldon, B.C. (2008). Adaptive phenotypic plasticity in response to climate change in a wild bird population. Science 320, 800-803.

Charnov, E.L. (2003). Life history invariants: Some explorations of symmetry in evolutionary ecology. Oxford Series in Ecology and Evolution Oxford University Press, Oxford, UK, $168 \mathrm{pp}$.

Chase, J.M. (2007). Drought mediates the importance of stochastic community assembly. Proc. Natl. Acad. Sci. USA 104, 17430-17434.

Chown, S.L., and Gaston, K.J. (2000). Island hopping invaders hitch a ride with tourists in the Southern Ocean. Nature 408, 637.

Clarke, A. (1983). Life in cold water: The physiological ecology of polar marine ectotherms. Oceanogr. Mar. Biol. Annu. Rev. 21, 341-453.

Clarke, A. (2006). Temperature and the metabolic theory of ecology. Funct. Ecol. 20, 405-412.

Clarke, A., and Fraser, K.P.P. (2004). Why does metabolism scale with temperature? Funct. Ecol. 18, 243-251.

Clarke, A., and Johnston, N.M. (1999). Scaling of metabolic rate with body mass and temperature in teleost fish. J. Anim. Ecol. 68, 893-905.

Clarke, A., Aronson, R.B., Crame, J.A., Gili, J.M., and Blake, D.B. (2004). Evolution and diversity of the benthic fauna of the Southern Ocean Continental Shelf. Antarct. Sci. 16, 559-568.

Cohen, J.E., Jonsson, T., and Carpenter, S.R. (2003). Ecological community description using the food web, species abundance, and body size. Proc. Natl. Acad. Sci. USA 100, 1781-1786.

Cohen, J.E., Jonsson, T., Muller, C.B., Godfray, H.C.J., and Savage, V.M. (2005). Body sizes of hosts and parasitoids in individual feeding relationships. Proc. Natl. Acad. Sci. USA 102, 684-689. 
Cox, P.M., Betts, R.A., Jones, C.D., Spall, S.A., and Totterdell, I.J. (2000). Acceleration of global warming due to carbon-cycle feedbacks in a coupled climate model. Nature 408, 184-187.

Cross, W.F., Benstead, J.P., Rosemond, A.D., and Wallace, J.B. (2003). Consumerresource stoichiometry in detritus-based streams. Ecol. Lett. 6, 721-732.

Cross, W.F., Benstead, J.P., Frost, P.C., and Thomas, S.A. (2005). Ecological stoichiometry in freshwater benthic systems: Recent progress and perspectives. Freshw. Biol. 50, 1895-1912.

Cushing, D.H. (1975). Marine Ecology and Fisheries. Cambridge University Press, Archive, 279 pp.

Cyr, H., and Curtis, J.M. (1999). Zooplankton community size structure and taxonomic composition affects size-selective grazing in natural communities. Oecologia 118, 306-315.

Daehler, C.C., and Strong, D.R. (1996). Can you bottle nature? The roles of microcosms in ecological research. Ecology 77, 663-664.

Daufresne, M., Lengfellner, K., and Sommer, U. (2009). Global warming benefits the small in aquatic ecosystems. Proc. Natl. Acad. Sci. USA 106, 12788-12793.

Davidson, E.A., and Janssens, I.A. (2006). Temperature sensitivity of soil carbon decomposition and feedbacks to climate change. Nature 440, 165-173.

Davis, A.J., Jenkinson, L.S., Lawton, J.H., Shorrocks, B., and Wood, S. (1998). Making mistakes when predicting shifts in species range in response to global warming. Nature 391, 783-786.

Dayton, P.K. (1990). Polar benthos. In: Polar Oceanography, Part B: Chemistry, Ecology and Geology (Ed. by W.O. Smith, Jr.), pp. 631-685. Academic Press, London.

Demott, W.R., Gulati, R.D., and Van Donk, E. (2001). Effects of dietary phosphorus deficiency on the abundance, phosphorus balance, and growth of Daphnia cucullata in three hypereutrophic Dutch lakes. Limnol. Oceanogr. 46, 1871-1880.

Deutsch, C.A., Tewksbury, J.J., Huey, R.B., Sheldon, K.S., Ghalambor, C.K., Haak, D.C., and Martin, P.R. (2008). Impacts of climate warming on terrestrial ectotherms across latitude. Proc. Natl. Acad. Sci. USA 105, 6668-6672.

Douglas, M.S.V., Smol, J.P., and Blake, W. (1994). Marked post- $18^{\text {th }}$ century environmental change in high-Arctic ecosystems. Science 266, 416-419.

Droop, M.R. (1983). 25 years of algal growth kinetics: A personal view. Bot. Mar. 26, 99-112.

Dunham, A.E., Grant, B.W., and Overall, K.L. (1989). Interfaces between biophysical and physiological ecology and the population ecology of terrestrial vertebrate ectotherms. Physiol. Zool. 62, 335-355.

Dunne, J.A., Williams, R.J., Martinez, N.D., Wood, R.A., and Erwin, D.E. (2008). Compilation and network analyses of Cambrian food webs. PLoS Biol. 6, 693-708.

Durance, I., and Ormerod, S.J. (2007). Effects of climatic variation on upland stream invertebrates over a 25 year period. Global Change Biol. 13, 942-957.

Durance, I., and Ormerod, S. (2009). Trends in water quality and discharge confound long-term warming effects on river macroinvertebrates. Freshw. Biol. 54, 388-405.

Durant, J.M., Hjermann, D.O., Ottersen, G., and Stenseth, N.C. (2007). Climate and the match or mismatch between predator requirements and resource availability. Climate Res. 33, 271-283.

Elser, J.J., and Hessen, D.O. (2005). Biosimplicity via stochiometry; The evolution of food web structure and processes. In: Aquatic Food Webs: An Ecosystem Approach (Ed. by A. Belgrano, U.M. Scharler, J. Dunne and R.E. Ulanowicz), pp. 7-18. Oxford University Press, Oxford, UK. 
Elser, J.J., Fagan, W.F., Denno, R.F., Dobberfuhl, D.R., Folarin, A., Huberty, A., Interlandi, S., Kilham, S.S., McCauley, E., Schulz, K.L., Siemann, E.H., and Sterner, R.W. (2000). Nutritional constraints in terrestrial and freshwater food webs. Nature 408, 578-580.

Emerson, B.C., and Gillespie, R.G. (2008). Phylogenetic analysis of community assembly and structure over space and time. Trends Ecol. Evol. 23, 619-630.

Emmerson, M., and Raffaelli, D. (2004). Predator-prey body size, interaction strength and the stability of a real food web. J. Anim. Ecol. 73, 399-409.

Emmerson, M., Bezemer, T.M., Hunter, M.D., and Jones, T.H. (2005a). Global change alters the stability of food webs. Global Change Biol. 11, 490-501.

Emmerson, M.E., Montoya, J.M., and Woodward, G. (2005b). Allometric scaling and body-size constraints in complex food webs. In: Dynamic Food Webs: Multispecies Assemblages, Ecosystem Development, and Environmental Change (Ed. by P.C. de Ruiter, V. Wolters and J.C. Moore). Academic Press, San Diego, USA.

Feuchtmayr, H., Moran, R., Hatton, K., Connor, L., Heyes, T., Moss, B., Harvey, I., and Atkinson, D. (2009). Global warming and eutrophication: Effects on water chemistry and autotrophic communities in experimental hypertrophic shallow lake mesocosms. J. Appl. Ecol. 46, 713-723.

Finkel, Z.V., Beardall, J., Flynn, K.J., Quigg, A., Rees, T.A.V., and Raven, J.A. (2010). Phytoplankton in a changing world: Cell size and elemental stoichiometry. J. Plankton Res. 32, 119-137.

Flory, E.A., and Milner, A.M. (1999). The role of competition in invertebrate community development in a recently formed stream in Glacier Bay National Park, Alaska. Aquat. Ecol. 33, 175-184.

Fonseca, C.R., and Ganade, G. (1996). Asymmetries, compartments and null interactions in an Amazonian ant-plant community. J. Anim. Ecol. 65, 339-347.

Forrest, J., Inouye, D.W., and Thomson, J.D. (2010). Flowering phenology in subalpine meadows: Does climate variation influence community co-flowering patterns? Ecology 91, 431-440.

Fox, J.W., and Morin, P.J. (2001). Effects of intra- and interspecific interactions on species responses to environmental change. J. Anim. Ecol. 70, 80-90.

Friberg, N., Christensen, J.B., Olafsson, J.S., Gislason, G.M., Larsen, S.E., and Lauridsen, T.L. (2009). Relationship between structure and function in streams contrasting in temperature: Possible impacts of climate change on running water ecosystems. Freshw. Biol. 54, 2051-2068.

Frost, P.C., and Elser, J.J. (2002). Growth responses of littoral mayflies to the phosphorus content of their food. Ecol. Lett. 5, 232-240.

Frost, P.C., Tank, S.E., Turner, M.A., and Elser, J.J. (2003). Elemental composition of littoral invertebrates from oligotrophic and eutrophic Canadian lakes. J. N. Am. Benthol. Soc. 22, 51-62.

Frost, P.C., Evans-White, M.A., Finkel, Z.V., Jensen, T.C., and Matzek, V. (2005). Are you what you eat? Physiological constraints on organismal stoichiometry in an elementally imbalanced world. Oikos 109, 18-28.

Frost, P.C., Benstead, J.P., Cross, W.F., Hillebrand, H., Larson, J.H., Xenopoulos, M.A., and Yoshida, T. (2006). Threshold elemental ratios of carbon and phosphorus in aquatic consumers. Ecol. Lett. 9, 774-779.

Geider, R.J., Macintyre, H.L., and Kana, T.M. (1998). A dynamic regulatory model of phytoplanktonic acclimation to light, nutrients, and temperature. Limnol. Oceanogr. 43, 679-694. 
Giguere, L.A. (1981). Food assimilation efficiency as a function of temperature and meal size in larvae of Chaoborus trivittatus (Diptera: Chaoboridae). J. Anim. Ecol. 50, 103-109.

Gillooly, J., Brown, J.H., West, G.B., Savage, V.M., and Charnov, E.L. (2001). Effects of size and temperature on metabolic rate. Science 293, 2248-2251.

Gillooly, J.F., Allen, A.P., Brown, J.H., Elser, J.J., Martinez del Rio, C., Savage, V.M., West, G.B., Woodruff, W.H., and Woods, H.A. (2005). The metabolic basis of whole-organism RNA and phosphorus content. Proc. Natl. Acad. Sci. USA 102, 11923-11927.

Giordano, M., Beardall, J., and Raven, J.A. (2005). $\mathrm{CO}_{2}$ concentrating mechanisms in algae: Mechanisms, environmental modulation, and evolution. Annu. Rev. Plant Biol. 56, 99-131.

Gnanadesikan, A. (1999). A simple predictive model for the structure of the oceanic pycnocline. Science 283, 2077-2079.

González, A. (2000). Community relaxation in fragmented landscapes: The relation between species richness, area and age. Ecol. Lett. 3, 441-448.

González, A., Kominoski, J.S., Danger, M., Ishida, S., Iwai, N., and Rubach, A. (2010). Can ecological stoichiometry help explain patterns of biological invasions? Oikos 119, 779-790.

Gray, J.S. (2001). Antarctic marine benthic biodiversity in a world-wide latitudinal context. Polar Biol. 24, 633-641.

Hagiwara, A., Yamamiya, N., and Belem de Araujo, A. (1998). Effect of water viscosity on the population growth of the rotifer Brachionus plicatilis Muller. Hydrobiology 387-388, 489-494.

Hannah, D.M., Brown, L.E., Milner, A.M., Gurnell, A.M., McGregor, G.R., Petts, G.E., Smith, B.P.G., and Snook, D.L. (2007). Integrating climatehydrology-ecology for alpine river systems. Aquat. Conserv.: Mar Freshw. Ecosyst. 17, 636-656.

Hari, R.E., Livingstone, D.M., Siber, R., Burkhardt-Holm, P., and Guttinger, H. (2006). Consequences of climate change for water temperature and brown trout populations in Alpine rivers and streams. Global Change Biol. 12, 10-26.

Harmon, J.P., Moran, N.A., and Ives, A.R. (2009). Species response to environmental change: Impacts of food web interactions and evolution. Science 323, 1347-1350.

Harper, M.P., and Peckarsky, B.L. (2006). Emergence cues of a mayfly in a highaltitude stream ecosystem: Potential response to climate change. Ecol. Appl. 16, 612-621.

Harris, R.M.L., Milner, A.M.M., Armitage, P.D., and Ledger, M.E. (2007). Replicability of physicochemistry and macroinvertebrate assemblages in stream mesocosms: Implications for experimental research. Freshw. Biol. 52, 2434-2443.

Harrison, G.W. (1995). Comparing predator prey models to Lucknbills's experiment with Didinium and Paramecium. Ecology 76, 357-374.

Hassell, M.P. (2000). The spatial and temporal dynamics of host-parasitoid interactions. Oxford University Press, $154 \mathrm{pp}$.

Hays, G.C., Richardson, A.J., and Robinson, C. (2005). Climate change and marine plankton. Trends Ecol. Evol. 20, 337-344.

Hedgpeth, J.W. (1971). Perspectives of benthic ecology in Antarctica. In: Research in the Antarctic (Ed. by L.O. Quam), pp. 93-136. American Association for the Advancement of Science, Washington.

Hegland, S.J., Nielsen, A., Lázaro, A., Bjerknes, A.-L., and Totland, Ø. (2009). How does climate warming affect plant-pollinator interactions? Ecol. Lett. 12, 184-195. 
Henneman, M.L., and Memmott, J. (2001). Infiltration of a Hawaiian community by introduced biological control agents. Science 293, 1314-1316.

Hessen, D.O., Faerovig, P.J., and Andersen, T. (2002). Light, nutrients, and P:C ratios in algae: Grazer performance related to food quality and quantity. Ecology 83, 1886-1898.

Hessen, D.O., Agren, G.I., Anderson, T.R., Elser, J.J., and De Ruiter, P.C. (2004). Carbon, sequestration in ecosystems: The role of stoichiometry. Ecology 85, 1179-1192.

Hessen, D.O., van Donk, E., and Gulati, R. (2005). Seasonal seston stoichiometry: Effects on zooplankton in cyanobacteria-dominated lakes. J. Plankton Res. 27, 449-460.

Hickling, R., Roy, D.B., Hill, J.K., Fox, R., and Thomas, C.D. (2006). The distributions of a wide range of taxonomic groups are expanding polewards. Global Change Biol. 12, 450-455.

Hildrew, A.G. (2009). Sustained research on stream communities: A model system and the comparative approach. Adv. Ecol. Res. 41, 175-312.

Hladyz, S., Gessner, M.O., Giller, P.S., Pozo, J., and Woodward, G. (2009). Resource quality and stoichiometric constraints in a stream food web. Freshw. Biol. 54, 957-970.

Hogg, I.D., Williams, D.D., Eadie, J.M., and Butt, S.A. (1995). The consequences of global warming for stream invertebrates: A field simulation. J. Thermal Biol. 20, 199-206.

Høye, T.T., Post, E., Meltofte, H., Schmidt, N.M., and Forchhammer, M.C. (2007). Rapid advancement of spring in the High Arctic. Curr. Biol. 17, R449-R451.

Hulle, M., Bonhomme, J., Maurice, D., and Simon, J.C. (2008). Is the life cycle of high arctic aphids adapted to climate change? Polar Biol. 31, 1037-1042.

Hunt von Herbing, I., and Keating, K. (2003). Temperature-induced changes in viscosity and its effects on swimming speed in larval haddock. The Big Fish Bang, Proceedings of the 26th Annual Larval Fish Conference, 23-34.

Ims, R.A., and Fuglei, E. (2005). Trophic interaction cycles in tundra ecosystems and the impact of climate change. Bioscience 55, 311-322.

Ings, T.C., Montoya, J.M., Bascompte, J., Bluthgen, N., Brown, L., Dormann, C.F., Edwards, F., Figueroa, D., Jacob, U., Jones, J.I., Lauridsen, R.B., Ledger, M.E., et al. (2009). Ecological networks-Beyond food webs. J. Anim. Ecol. 78, 253-269.

Inouye, D.W. (2008). Effects of climate change on phenology, frost damage, and floral abundance of montane wildflowers. Ecology 89, 353-362.

Inouye, D.W., Saavedra, F., and Lee-Wang, W. (2003). Environmental influences on the phenology and abundance of flowering by Androsace septentrionalis (Primulaceae). Am. J. Bot. 90, 905-910.

IPCC Climate Change (2007). The Physical Sciences Basis. In: Contribution of Working Group I to the Fourth Assessment Report of the Intergovernmental Panel on Climate Change (Ed. by M. Parry, O. Canziani, J. Palutkof, P. Van der Linden and C. Hanson). Cambridge University Press, Cambridge, UK.

Ives, A.R., and Zhu, J. (2006). Statistics for correlated data: phylogenies, space, and time. Ecol. Appl. 16, 20-32.

Jacob, U. (2005). Trophic Dynamics of Antarctic Shelf Ecosystems-Food Webs and Energy Flow Budgets. University of Bremen, Germany, PhD Thesis, 125 pp.

Jacob, U., Terpstra, S., and Brey, T. (2003). The role of depth and feeding in regular sea urchins niche separation-An example from the high Antarctic Weddell Sea. Polar Biol. 26, 99-104. 
Jennings, S.J., and Brander (2010). Predicting the effects of climate change on marine communities and the consequences for fisheries. J. Mar. Syst. 79, 418-426.

Jeppesen, E., Søndergaard, M., and Jensen, J.P. (2003). Climatic warming and regime shifts in lake food webs: Some comments. Limnol. Oceanogr. 48, 1346-1349.

Jeyasingh, P.D. (2007). Plasticity in metabolic allometry: The role of dietary stoichiometry. Ecol. Lett. 10, 282-289.

Jiang, L., and Morin, P.J. (2004). Temperature-dependent interactions explain unexpected responses to environmental warming in communities of competitors. J. Anim. Ecol. 73, 569-576.

Johnson, E.A., and Miyanishi, K. (2008). Testing the assumptions of chronosequences in succession. Ecol. Lett. 11, 419-431.

Jones, T.S., Godfray, H.C.J., and van Veen, F.J.F. (2009). Resource competition and shared natural enemies in experimental insect communities. Oecologia 159, $627-635$.

Jonsson, T., Cohen, J.E., and Carpenter, S.R. (2005). Food webs, body size, and species abundance in ecological community description. Adv. Ecol. Res. 36, 1-84.

Jordano, P. (1987). Patterns of mutualistic interactions in pollination and seed dispersal: Connectance, dependence asymmetries, and coevolution. Am. Nat. 657-677.

Jordano, P., Bascompte, J., and Olesen, J.M. (2003). Invariant properties in coevolutionary networks of plant-animal interactions. Ecol. Lett. 6, 69-81.

Jordano, P., Bascompte, J., and Olesen, J.M. (2006). The ecological consequences of complex topology and nested structure in pollination webs. In: Plant-pollinator interactions: From specialization to generalization (Ed. by N.M. Waser and J. Ollerton), pp. 173-199. University of Chicago Press, Chicago.

Jordano, P., Vázquez, D.P., and Bascompte, J. (2010). Redes complejas de interaccions mutualistas planta-animal. In: Ecología y evolución de interacciones plantaanimal: conceptos y applicaciones (Ed. by R. Medel, M.A. Aizen and R. Zamora), pp. 17-41. Edotorial Universitaria, Santiago de Chile.

Kingsolver, J., and Woods, H. (1998). Interactions of temperature and dietary protein concentration in growth and feeding of Manduca sexta caterpillars. Physiol. Entomol. 23, 354-359.

Kishi, D., Murakami, M., Nakano, S., and Maekawa, K. (2005). Water temperature determines strength of top-down control in a stream food web. Freshw. Biol. 50, $1315-1322$.

Kissling, W.D., Field, R., Korntheuer, H., Heyder, U., and Böhning-Gaese, K. (2010). Woody plants and the prediction of climate-change impacts on bird diversity. Philos. Trans. R. Soc. Lond. B 365, 2035-2045.

Klausmeier, C.A., Litchman, E., and Levin, S.A. (2004a). Phytoplankton growth and stoichiometry under multiple nutrient limitation. Limnol. Oceanogr. 49, 1463-1470.

Klausmeier, C.A., Litchman, E., Daufresne, T., and Levin, S.A. (2004b). Optimal nitrogen-to-phosphorus stoichiometry of phytoplankton. Nature 429, 171-174.

Kohfeld, K.E., Quere, C.L., Harrison, S.P., and Anderson, R.F. (2005). Role of marine biology in glacial-interglacial $\mathrm{CO}_{2}$ cycles. Science 308, 74-78.

Kokkoris, G.D., Troumbis, A.Y., and Lawton, J.H. (2002). Patterns of species interaction strength in assembled theoretical competition communities. Ecol. Lett. 2, 70-74.

Kominoski, J.S., Moore, P.A., Wetzel, R.G., and Tuchman, N.C. (2007). Elevated $\mathrm{CO}_{2}$ alters leaf-litter-derived dissolved organic carbon: Effects on stream periphyton and crayfish feeding preference. J. N. Am. Benthol. Soc. 26, 663-672. 
Konig, K.A., Kamenik, C., Schmidt, R., Agustí-Panareda, A., Appleby, P., Lami, A., Prazakova, M., Rose, N., Schnell, O.A., Tessadri, R., Thompson, R., and Psenner, R. (2002). Environmental changes in an alpine lake (Gossenköllesee, Austria) over the last two centuries-The influence of air temperature on biological parameters. J. Paleolimnol. 28, 147-160.

Kratz, T.K., Deegan, L.A., Harmon, M.E., and Lauenroth, W.K. (2003). Ecological variability in space and time: Insights gained from the US LTER Program. Bioscience 53, 57-67.

Lafferty, K.D., Allesina, S., Arim, M., Briggs, C.J., DeLeo, G., Dobson, A., Dunne, J.A., Johnson, P.T.J., Kuris, A.M., Marcogliese, D.J., Martinez, N.D., Memmott, J., et al. (2008). Parasites in food webs: The ultimate missing links. Ecol. Lett. 11, 533-546.

Lagergren, R., Lord, H., and Stenson, J.A.E. (2000). Influence of temperature on hydrodynamic costs of morphological defences in zooplankton: Experiments on models of Eubomina (Cladocera). Funct. Ecol. 14, 380-387.

Lane, A.M.J. (1997). The U.K. Environmental Change Network database: An integrated information resource for long-term monitoring and research. J. Environ. Manage. 51, 87-105.

Lanfear, R., Thomas, J.A., Welch, J.J., Brey, T., and Bronham, L. (2007). Metabolic rate does not calibrate the molecular clock. Proc. Natl. Acad. Sci. USA 104, $15388-15393$.

Langford, T.E. (1990). Ecological effects of thermal discharges. Pollution Monitoring Series. Elsevier Applied Science, 468 pp. UK.

Larsen, P.S., Madsen, C.V., and Riisgard, H.U. (2008). Effect of temperature and viscosity on swimming velocity of the copepod Acartia tonsa, brine shrimp Artemia salina and rotifer Brachionus plicatilis. Aquat. Biol. 4, 47-54.

Lavandier, P., and Décamps, H. (1983). Un torrent d'altitude dans les Pyrénées: l'Estaragne. In: Ecosystèmes Limniques (Ed. by F. Bourlière and M. Lamotte), pp. 81-111. Masson, Paris.

Laws, E.A., Falkowski, P.G., Smith, W.O.J., et al. (2000). Temperature effects on export production in the open ocean. Global Biogeochem. Cycle 14, 1231-1246.

Layer, K., Hildrew, A.G., Monteith, D., and Woodward, G. (2010a). Long-term variation in the littoral food web of an acidified mountain lake. Global Change Biol. 10.1111/j.1365-2486.2010.02195.x (in press).

Layer, K., Riede, J.O., Hildrew, A.G., and Woodward, G. (2010b). Food web structure and stability in 20 streams across a wide pH gradient. Adv. Ecol. Res. 42.

Ledger, M.E., and Hildrew, A.G. (2001). Recolonization by the benthos of an acid stream following a drought. Arch. Hydrobiol. 152, 1-17.

Ledger, M.E., and Hildrew, A.G. (2005). The ecology of acidification: Patterns in stream food webs across a $\mathrm{pH}$ gradient. Environ. Pollut. 137, 103-118.

Ledger, M.E., Harris, R.M.L., Armitage, P.D., and Milner, A.M. (2008). Disturbance frequency influences patch dynamics in stream benthic algal communities. Oecologia 155, 809-819.

Ledger, M.E., Harris, R.M.L., Armitage, P.D., and Milner, A.M. (2009). Realism of model ecosystems: An evaluation of physicochemistry and macroinvertebrate assemblages in artificial streams. Hydrobiologia 617, 91-99.

Liboriussen, L., Landkildehus, F., Meerhoff, M., Bramm, M.E., Søndergaard, M., Christoffersen, K., Richardson, K., Søndergaard, M., Lauridsen, T.L., and Jeppesen, E. (2005). Global warming: Design of a flow-through shallow lake mesocosm climate experiment. Limnol. Oceanogr.: Methods 3, 1-9. 
Litchman, E., Klausmeier, C.A., and Bossard, P. (2004). Phytoplankton nutrient competition under dynamic light regimes. Limnol. Oceanogr. 49, 1457-1462.

Litchman, E., Klausmeier, C.A., Schofield, O.M., and Falkowski, P.G. (2007). The role of functional traits and trade-offs in structuring phytoplankton communities: Scaling from cellular to ecosystem level. Ecol. Lett. 10, 1170-1181.

Litchman, E., Klausmeier, C.A., and Yoshiyama, K. (2009). Contrasting size evolution in marine and freshwater diatoms. Proc. Natl. Acad. Sci. USA 106, 2665-2670.

Loiterton, B., Sundbom, M., and Vrede, T. (2004). Separating physical and physiological effects of temperature on zooplankton feeding rate. Aquat. Sci. 66, 13-129.

Lopez-Urrutia, A., San Martin, E., Harris, R.P., and Irigoien, X. (2006). Scaling the metabolic balance of the oceans. Proc. Natl. Acad. Sci. USA 103, 8739-8744.

Luckinbill, L.S. (1973). Coexistence in laboratory populations of Paramecium aurelia and its predator Didinium nasutum. Ecology 54, 1320-1327.

Macfadyen, S., Gibson, R., Raso, L., Sint, D., Traugott, M., and Memmott, J. (2009). Parasitoid control of aphids in organic and conventional farming systems. Agr. Ecosyst. Environ. 133, 14-18.

Machmer, H. (1972). Ciliary activity and the origin of metachrony in Paramecium: Effects of increased viscosity. J. Exp. Biol. 57, 239-259.

Marquet, P.A., Navarrete, S.A., and Castilla, J.C. (1990). Scaling population density to body size in rocky intertidal communities. Science 250, 1125-1127.

May, R.M. (1972). Will a large complex system be stable? Nature 238, 413-414.

May, R.M. (1973). Stability and Complexity in Model Ecosystems. Princeton University Press, Princeton.

McCann, K., Hastings, A., and Huxel, G.R. (1998). Weak trophic interactions and the balance of nature. Nature 395, 794-798.

McKee, D., Atkinson, D., Collings, S.E., Eaton, J.W., Gill, A.B., Harvey, I., Hatton, K., Heryes, T., Wilson, D., and Moss, B. (2003). Response of freshwater microcosm communities to nutrients, fish, and elevated temperature during winter and summer. Limnol. Oceanogr. 48, 707-722.

McLaughlin, O.B., Jonsson, T., and Emmerson, M.C. (2010). Temporal variability in predator-prey relationships of a forest floor food web. Adv. Ecol. Res. 42, 171-264.

Meerhoff, M., Clemente, J.M., De Mello, F.T., Iglesias, C., Pedersen, A.R., and Jeppesen, E. (2007). Can warm climate-related structure of littoral predator assemblies weaken the clear water state in shallow lakes? Global Change Biol. 13, 1888-1897.

Memmott, J., Craze, P.G., Waser, N.M., and Price, M.V. (2007). Global warming and the disruption of plant-pollinator interactions. Ecol. Lett. 10, 710-717.

Milly, P.C.D., Dunne, K.A., and Vecchia, A.V. (2006). Global pattern of trends in streamflow and water availability in a changing climate. Nature 438, 347-350.

Milner, A.M., Knudsen, E.E., Soiseth, C., Robertson, A.L., Schell, D., Phillips, I.T., and Magnusson, K. (2000). Colonization and development of stream communities across a 200-year gradient in Glacier Bay National Park, Alaska. Can. J. Fish. Aquat. Sci. 57, 2319-2335.

Milner, A.M., Robertson, A.E., Monaghan, K., Veal, A.J., and Flory, E.A. (2008). Colonization and development of a stream community over 28 years; Wolf Point Creek in Glacier Bay, Alaska. Front. Ecol. Environ. 6, 413-419.

Milner, A.M., Brown, L.E., and Hannah, D.M. (2009). Hydroecological effects of shrinking glaciers. Hydrol. Process. 23, 62-77.

Mohseni, O., and Stefan, H.G. (1999). Stream temperature/air temperature relationship: A physical interpretation. J. Hydrol. 218, 128-141. 
Montoya, J.M., and Raffaelli, D. (2010). Climate change, biotic interactions and ecosystem services. Philos. Trans. R. Soc. Lond. B 365, 2013-2018.

Montoya, J.M., Pimm, S.L., and Solé, R.V. (2006). Ecological networks and their fragility. Nature 442, 259-264.

Montoya, J.M., Woodward, G., Emmerson, M.C., and Sole, R.C. (2009). Indirect effects propagate disturbances in real food webs. Ecology 90, 2426-2433.

Moore, J.C., Berlow, E.L., Coleman, D.C., de Ruiter, P.C., Dong, Q., Hastings, A., Johnson, N.C., McCann, K.S., Melville, K., Morin, P.J., Nadelhoffer, K., Rosemond, A.D., et al. (2004). Detritus, trophic dynamics and biodiversity. Ecol. Lett. 7, 584-600.

Moran, X.A., López-Urrutia, Á., Calvo-Díaz, A., and Li, W.K.W. (2010). Increasing importance of small phytoplankton in a warmer ocean. Global Change Biol. 16, $1137-1144$.

Moss, B., McKee, D., Atkinson, D., Collings, S.E., Eaton, J.W., Gill, A.B., Harvey, I., Hatton, K., Heyes, T., and Wilson, D. (2003). How important is climate? Effects of warming, nutrient addition and fish on phytoplankton in shallow lake microcosms. J. Appl. Ecol. 40, 782-792.

Mulder, C., and Elser, J.J. (2009). Soil acidity, ecological stoichiometry and allometric scaling in grassland food webs. Global Change Biol. 15, 2730-2738.

Muller, H., and Geller, W. (1993). Maximum growth-rates of aquatic ciliated protozoa-The dependence on body size and temperature reconsidered. Arch. Hydrobiol. 126, 315-327.

Nilsson, L.A. (1988). The evolution of flowers with deep corolla tubes. Nature 334, 147-149.

Norby, R.J., Cotrufo, M.F., Ineson, P., O’Neill, E.G., and Canadell, J.G. (2001). Elevated $\mathrm{CO}_{2}$, litter chemistry, and decomposition: A synthesis. Oecologia 127, 153-165.

O'Gorman, E.J., and Emmerson, M.C. (2009). Perturbations to trophic interactions and the stability of complex food webs. Proc. Natl. Acad. Sci. USA 106, 13393-13398.

O'Gorman, E.J., and Emmerson, M.C. (2010). Manipulating interaction strengths and the consequences for trivariate patterns in a marine food web. Adv. Ecol. Res. 42, 301-419.

O'Gorman, E.J., Enright, R.A., and Emmerson, M.C. (2008). Predator diversity enhances secondary production and decreases the likelihood of trophic cascades. Oecologia 158, 557-567.

Olesen, J.M., and Jordano, P. (2002). Geographic patterns in plant-pollinator mutualistic networks. Ecology 83, 2416-2424.

Olesen, J.M., Bascompte, J., Elberling, H., and Jordano, P. (2008). Temporal dynamics of a pollination network. Ecology 89, 1573-1582.

Olesen, J.M., Dupont, Y.L., O’Gorman, E.J., Ings, T.C., Layer, K., Melián, C.J., Troejelsgaard, K., Pichler, D.E., Rasmussen, C., and Woodward, G. (2010). From Broadstone to Zackenberg: Space, time and hierarchies in ecological networks. Adv. Ecol. Res. 42, 1-69.

Parker, S.M., and Huryn, A.D. (2006). Food web structure and function in two arctic streams with contrasting disturbance regimes. Freshw. Biol. 51, 1249-1263.

Parmesan, C. (2006). Ecological and evolutionary responses to recent climate change. Ann. Rev. Ecol. Evol. Syst. 37, 637-669.

Parmesan, C., and Yohe, G. (2003). A globally coherent fingerprint of climate change impacts across natural systems. Nature 421, 37-42. 
Pearson, R.G., and Dawson, T.P. (2003). Predicting the impacts of climate change on the distribution of species: Are bioclimate envelope models useful? Global Ecol. Biogeogr. 12, 361-371.

Pelejero, C., Calvo, E., and Hoegh-Guldberg, O. (2010). Paleo-perspectives on ocean acidification. Trends Ecol. Evol. 25, 332-344.

Perkins, D.M., Reiss, J., Yvon-Durocher, G., and Woodward, G. (2010). Global change and food webs in running waters. Hydrobiologia (in press).

Perry, R.I., Cury, P., Brander, K., Jennings, S., Möllmann, C., and Planque, B. (2010). Sensitivity of marine systems to climate and fishing: Concepts, issues and management responses. J. Mar. Syst. 79, 427-435.

Petchey, O.L., and Belgrano, A. (2010). Body-size distributions and size-spectra: universal indicators of ecological status? Biol. Lett. 6, 434-437.

Petchey, O.L., Beckerman, A.P., Riede, J.O., and Warren, P.H. (2008). Size, foraging, and food web structure. Proc. Natl. Acad. Sci. USA 105, 4191-4196.

Petchey, O.L., McPhearson, P.T., Casey, T.M., and Morin, P.J. (1999). Environmental warming alters food-web structure and ecosystem function. Nature 402, 69-72.

Petchey, O.L., Casey, T.J., Jiang, L., McPhearson, P.T., and Price, J. (2002). Species richness, environmental fluctuations, and temporal change in total community biomass. Oikos 99, 231-240.

Petchey, O.L., Brose, U., and Rall, B.C. (2010). Predicting the effects of temperature on food web connectance. Philos. Trans. R. Soc. Lond. B 365, 2081-2091.

Peters, R.H. (1983). In: The Ecological Implications of Body Size (Ed. by E. Beck, H.J.B. Birks and E.F. Connor), pp. 24-44. Cambridge University Press, Cambridge, UK.

Piechnik, D.A., Lawler, S.P., and Martinez, N.D. (2008). Food-web assembly during a classic biogeographic study: Species" "trophic breadth" corresponds to colonization order. Oikos 117, 665-674.

Podolsky, R.D. (1994). Temperature and water viscosity: Physiological versus mechanical effects on suspension feeding. Science 265, 100-103.

Podolsky, R.D., and Emlet, R.B. (1993). Separating the effects of temperature and viscosity on swimming and water movement by Sand Dollar larvae (Dendraster excentricus). J. Exp. Biol. 176, 207-221.

Pope, J.G., Shepherd, J.G., and Webb, J. (1994). Successful surf-riding on size spectra: The secret of survival in the sea. Philos. Trans. R. Soc. Lond. B 343, 41-49.

Pounds, J.A., Fogden, M.P.L., and Campbell, J.H. (1999). Biological response to climate change on a tropical mountain. Nature 398, 611-615.

Purcell (1977). Life at low Reynolds number. Am. J. Phys. 45, 1-11.

Raffaelli, D. (2004). How extinction patterns affect ecosystems. Science 306, 1141-1142.

Rahel, F.J., and Olden, J.D. (2008). Assessing the effects of climate change on aquatic invasive species. Conserv. Biol. 22, 521-533.

Rall, B.C., Vucic-Pestic, O., Ehnes, R.B., Emmerson, M.C., and Brose, U. (2010). Temperature, predator-prey interaction strength and population stability. Global Change Biol. 10.1111/j.1365-2486.2009.02124.x.

Rawcliffe, R., Sayer, C.D., Woodward, G., Grey, J., Davidson, T.A., and Jones, J.I. (2010). Back to the future: Using palaeolimnology to infer long-term changes in shallow lake food webs. Freshw. Biol. 55, 600-613.

Redfield, A.C. (1934). On the proportions of organic derivatives in sea water and their relation to the composition of plankton. In: James Johnstone Memorial Volume (Ed. by R.J. Daniel), pp. 176-192. Liverpool University Press, Liverpool. 
Reich, P.B., and Oleksyn, J. (2004). Global patterns of plant leaf N and P in relation to temperature and latitude. Proc. Natl. Acad. Sci. USA 101, 11001-11006.

Reiss, J., Bridle, J.R., Montoya, J.M., and Woodward, G. (2009). Emerging horizons in biodiversity and ecosystem functioning research. Trends Ecol. Evol. 24, 505-514.

Reuman, D.C., and Cohen, J.E. (2005). Estimating relative energy fluxes using the food web, species abundance, and body size. Adv. Ecol. Res. 36, 137-182.

Reuman, D.C., Mulder, C., Raffaelli, D., and Cohen, J.E. (2008). Three allometric relations of population density to body mass: Theoretical integration and empirical tests in 149 food webs. Ecol. Lett. 11, 1216-1228.

Reuman, D.C., Mulder, C., Banašek-Richter, C., Cattin Blandenier, M.-F., Breure, A.M., Den Hollander, H.A., Kneitel, J.M., Raffaelli, D., Woodward, G., and Cohen, J.E. (2009a). Allometry of body size and abundance in 166 food webs. Adv. Ecol. Res. 41, 1-44.

Reuman, D.C., Cohen, J.E., and Mulder, C. (2009b). Human and environmental factors influence soil food webs' abundance-mass allometry and structure. $A d v$. Ecol. Res. 41, 45-85.

Rhee, G.-Y., and Gotham, I.J. (1981). The effect of environmental factors on phytoplankton growth: Temperature and the interactions of temperature with nutrient limitation. Limnol. Oceanogr. 26, 635-648.

Richardson, A.J., and Schoeman, D.S. (2004). Climate impact on plankton ecosystems in the Northeast Atlantic. Science 305, 1609-1612.

Riede, J.O., Rall, B.C., Banasek-Richter, C., Navarrete, S.A., Wieters, E.A., and Brose, U. (2010). Scaling of food-web properties with diversity and complexity across ecosystems. Adv. Ecol. Res. 42, 139-170.

Riisgård, H.U., and Larsen, P.S. (2007). Viscosity of seawater controls beat frequency of water-pumping cilia and filtration rate of mussels Mytilus edulis. Mar. Ecol. Prog. Ser. 141-150.

Romanuk, T.N., Zhou, Y., Brose, U., Berlow, E.L., Williams, R.J., and Martinez, N. D. (2009). Predicting invasion success in complex ecological networks. Philos. Trans. R. Soc. Lond. B 364, 1743-1754.

Rooney, N., McCann, K., Gellner, G., and Moore, J.C. (2006). Structural asymmetry and the stability of diverse food webs. Nature 442, 265-269.

Sala, O.E., Chapin Iii, F.S., Armesto, J.J., Berlow, E., Bloomfield, J., Dirzo, R., Huber-Sanwald, E., Huenneke, L.F., Jackson, R.B., Kinzig, A., et al. (2000). Global biodiversity scenarios for the year 2100. Science 287, 1770-1774.

Sarmento, H., Montoya, J.M., Vázquez-Domínguez, E., Vaqué, D., and Gasol, J.M. (2010). Warming effects on marine microbial food web processes: How far can we go when it comes to predictions? Philos. Trans. R. Soc. Lond. B 365, 2137-2149.

Sarmiento, J.L. and Wofsy, S.C. (1999). A U.S. carbon cycle science plan: Report of the Carbon and Climate Working Group, U.S. Global Change Res. Program, Washington, DC

Sarmiento, J.L., Slater, R., Barber, R., Bopp, L., Doney, S.C., Hirst, A.C., Kleypas, J., Matear, R., Mikolajewicz, U., Monfray, P., Soldatov, V., Spall, S.A., et al. (2004). Response of ocean ecosystems to climate warming. Glob. Biogeochem. Cycles 18, 1-23.

Schneider, W.R., and Doetsch, R.N. (1974). Effect of viscosity on bacterial motility. Bacteriology 117, 696-701.

Schofield, O., Ducklow, H.W., Martinson, D.C., Meredith, M.P., Moline, M.A., and Frazer, W.R. (2010). How do polar marine ecosystems respond to rapid climate change? Science 328, 1520-1523. 
Seuront, L., and Vincent, D. (2008). Increased seawater viscosity, Phaeocystis globosa spring bloom and Temora longicornis feeding and swimming behaviours. Mar. Ecol. Prog. Ser 363, 131-145.

Short and Ward (1981b). Trophic ecology of three winter stoneflies (Plecoptera). Am. Mid Naturalist 105, 341-347.

Short, R.A., and Ward, J.V. (1981a). Benthic detritus dynamics in a mountain stream. Holarctic Ecol. 4, 32-35.

Sleigh, M.A. (1956). Metachronism and frequency of beat in the peristomial cilia of Stentor. J. Exp. Biol. 33, 15-28.

Smol, J.P., Wolfe, A.P., Birks, H.J.B., Douglas, M.S.V., Jones, V.J., Korhola, A., Pienitz, R., Rühland, K., Sorvari, S., Antoniades, D., et al. (2005). Climate-driven regime shifts in the biological communities of arctic lakes. Proc. Natl. Acad. Sci. USA 102, 4397-4402.

Snow, B.K., and Snow, D.W. (1972). Feeding niches of hummingbirds in a Trinidad valley. J. Anim. Ecol. 41, 471-485.

Sommer, U. (1996). Plankton ecology: The past two decades of progress. Naturwissenschaften 83, 293-301.

Spooner, D.E., and Vaughn, C.C. (2008). A trait-based approach to species' roles in stream ecosystems: Climate change, community structure, and material cycling. Oecologia 158, 307-317.

Stang, M., Klinkhamer, P.G.L., and van der Meijden, E. (2006). Size constraints and flower abundance determine the number of interactions in a plant-flower visitor web. Oikos 112, 111-121.

Stang, M., Klinkhamer, P.G.L., Waser, N.M., Stang, I., and van der Mejden, E. (2009). Size-specific interaction patterns and size matching in a plant-pollinator interaction web. Ann. Bot. Lond. 103, 1459-1469.

Statzner, B., Gore, J.A., and Resh, V.H. (1988). Hydraulic stream ecology: Observed patterns and potential applications. J. N. Am. Benthol. Soc. 7, 307-360.

Stegen, J.C., Enquist, B.J., and Ferriere, R. (2009). Advancing the metabolic theory of biodiversity. Ecol. Lett. 12, 1001-1015.

Sterner, R.W. (1997). Modelling interactions of food quality and quantity in homeostatic consumers. Freshw. Biol. 38, 473-481.

Sterner, R.W. (2004). A one-resource "stoichiometry"? Ecology 85, 1813-1816.

Sterner, R.W., and Elser, J.J. (2002). Ecological Stoichiometry: The Biology of Elements from Molecules to the Biosphere. Princeton University Press, Princeton.

Sterner, R.W., and Hessen, D.O. (1994). Algal nutrient limitation and the nutrition of aquatic herbivores. Annu. Rev. Ecol. Syst. 25, 1-29.

Sterner, R.W., Elser, J.J., Fee, E.J., Guildford, S.J., and Chrzanowski, T.H. (1997). The light:nutrient ratio in lakes: The balance of energy and materials affects ecosystem structure. Am. Nat. 150, 663-684.

Stiling, and Cornelissen (2007). How does elevated carbon dioxide $\left(\mathrm{CO}_{2}\right)$ affect plantherbivore interactions? A field experiment and meta-analysis of $\mathrm{CO}_{2}$-mediated changes on plant chemistry and herbivore performance. Global Change Biol. 9, $1823-1842$.

Strathdee, A.T., Bale, J.S., Block, W.C., Coulson, S.J., Hodkinson, I.D., and Webb, N.R. (1993). Effects of temperature elevation on a field population of Acyrthosiphon svalbardicum (Hemiptera, Aphididae) on Spitsbergen. Oecologia 96, 457-465.

Strecker, A.L., Cobb, T.P., and Vinebrooke, R.D. (2004). Effects of experimental greenhouse warming on phytoplankton and zooplankton communities in fishless alpine ponds. Limnol. Oceanogr. 49, 1182-1190. 
Sweeney, B.W., Vannote, R.L., and Dodds, P.J. (1986). Effects of temperature and food quality on growth and development of a mayfly, Leptophlebia intermedia. Can. J. Fish. Aquat. Sci. 43, 12-18.

Teixidó, N., Garrabou, J., Gutt, J., and Arntz, W.E. (2007). Iceberg disturbance and successional spatial patterns: The case of the shelf Antarctic benthic communities. Ecosystems 10, 143-158.

Thackeray, S.J., Sparks, T.H., Frederiksen, M., Burthe, S., Bacon, P.J., Bell, J.R., Botham, M.S., Brereton, T.M., Bright, P.W., Carvalho, L., Clutton-Brock, T., and Dawson, A. (2010). Trophic level asynchrony in rates of phenological change for marine, freshwater and terrestrial environments. Global Change Biol. 10.1111/ j.1365-2486.2010.02165.x(in press).

Thomas, C.D., Cameron, A., Green, R.E., Bakkenes, M., Beaumont, L.J., Collingham, Y.C., Erasmus, B.F.N., De Siqueira, M.F., Grainger, A., and Hannah, L. (2004). Extinction risk from climate change. Nature 427, 145-148.

Thompson, D.J. (1978). Towards a realistic predator prey model effect of temperature on functional response and life history of larvae of damselfly, Ischnura elegans. J. Anim. Ecol. 47, 757-767.

Timmermann, A., Oberhuber, J., Bacher, A., Esch, M., Latif, M., and Roeckner, E. (1999). Increased El Niño frequency in a climate model forced by future greenhouse warming. Nature 398, 694-697.

Tuchman, N.C., Wetzel, R.G., Rier, S.T., Wahtera, K.A., and Teeri, J.A. (2002). Elevated atmospheric $\mathrm{CO}_{2}$ lowers leaf litter nutritional quality for stream ecosystem food webs. Global Change Biol. 8, 163-170.

Tylianakis, J. (2009). Warming up food webs. Science 323, 1300-1301.

Tylianakis, J.M., Tscharntke, T., and Lewis, O.T. (2007). Habitat modification alters the structure of tropical host-parasitoid food webs. Nature 445, 202-205.

Tylianakis, J., Didham, R.K., Bascompte, J., and Wardle, D.A. (2008). Global change and species interactions in terrestrial ecosystems. Ecol. Lett. 11, 1351-1363.

Urabe, J., and Sterner, R.W. (1996). Regulation of herbivore growth by the balance of light and nutrients. Proc. Natl. Acad. Sci. USA 93, 8465-8469.

Urabe, J., Kyle, M., Makino, W., Yoshida, T., Andersen, T., and Elser, J.J. (2002). Reduced light increases herbivore production due to stoichiometric effects of light/ nutrient balance. Ecology 83, 619-627.

Urabe, J., Togari, J., and Elser, J.J. (2003). Stoichiometric impacts of increased carbon dioxide on a planktonic herbivore. Global Change Biol. 9, 818-825.

Van der Putten, W.H., Macel, M., and Visser, M.E. (2010). Predicting species distribution and abundance responses to climate change: Why it is essential to include biotic interactions across trophic levels. Philos. Trans. R. Soc. Lond. B 365, 2025-2034.

Van Veen, F.J.F., Van Holland, P.D., and Godfray, H.C.J. (2005). Stable coexistence in insect communities due to density- and trait-mediated indirect effects. Ecology 86, 1382-1389.

Van Veen, F.J.F., Memmott, J. and Godfray, H.C.J. (2006). Indirect effects, apparent competition and biological control. In: Trophic and Guild Interactions in Biological Control, pp. 145-169.

Vasseur, D.A., and McCann, K.S. (2005). A mechanistic approach for modeling temperature dependent consumer-resource dynamics. Am. Nat. 166, 184-198.

Vermaat, J.E., Dunne, J.A., and Gilbert, A.J. (2009). Major dimensions in food-web structure properties. Ecology 90, 278-282.

Visser, M.E., Holleman, L.J.M., and Caro, S.P. (2009). Temperature has a causal effect on avian timing of reproduction. Proc. R. Soc. B-Biol. Sci. 276, 2323-2331. 
Vitousek, P.M. (1982). Nutrient cycling and nutrient use efficiency. Am. Nat. 119, 553-572.

Walters, A.W., and Post, D.M. (2008). An experimental disturbance alters fish size structure but not food chain length in streams. Ecology 89, 3261-3267.

Walther, G.R. (2010). Community and ecosystem responses to recent climate change. Philos. Trans. R. Soc. Lond. B 365, 2019-2024.

Walther, G.-R., Post, E., Convey, P., Menzel, A., Parmesan, C., Beebee, T.J.C., Fromentin, J.-M., Hoegh-Guldberg, O., and Bairlein, F. (2002). Ecological responses to recent climate change. Nature 416, 389-395.

Warren, P.H. (1996). Structural constraints on food web assembly. In: Aspects of the Genesis and Maintenance of Biological Diversity (Ed. by M.E. Hochberg, J. Clobert and R. Barbault), pp. 142-161. Oxford University Press, Oxford, UK.

Watson, A.J., and Orr, J.C. (2003). Carbon dioxide fluxes in the global ocean. In: Ocean Biogeochemistry: The Role of the Ocean Carbon Cycle in Global Change (Ed. by M.J.R. Fasham), Global Change-The IGBP Seriespp. 123-143.

Weiher, E., and Keddy, P.A. (1999). Relative abundance and evenness patterns along diversity and biomass gradients. Oikos 355-361.

White, M.C., and Zhao, X.Q. (2009). A periodic Droop model for two species competition in a chemostat. Bull. Math. Biol. 71, 145-161.

Williams, R.J., and Martinez, N.D. (2000). Simple rules yield complex food webs. Nature 404, 180-183.

Wilson, K. (1984). A bibliography of Lough Hyne (Ine) 1687-1982. J. Life Sci. R. Dubl. S 5, 1-11.

Winder, M., and Schindler, D.E. (2004). Climate change uncouples trophic interactions in an aquatic ecosystem. Ecology 85, 2100-2106.

Winder, M., Reuter, J.E., and Schladow, S.G. (2009). Lake warming favours smallsized planktonic diatom species. Philos. Trans. R. Soc. Lond. B 276, 427-435.

Winet, H. (1976). Ciliary propulsion of objects in tubes-Wall drag on swimming Tetrahymena (Ciliata) in presence of mucin and other long-chain polymers. J. Exp. Biol. 64, 283-302.

Winfield, I.J., Hateley, J., Fletcher, J.M., James, J.B., Bean, C.W., and Clabburn, P. (2010). Population trends of Arctic charr (Salvelinus alpinus) in the UK: Assessing the evidence for a widespread decline in response to climate change. Hydrobiologia 650, 55-65.

Witze, A. (2008). Losing Greenland. Nature 452, 798-802.

Woods, H.A., Makino, W., Cotner, J.B., Hobbie, S.E., Harrison, J.F., Acharya, K., and Elser, J.J. (2003). Temperature and the chemical composition of poikilothermic organisms. Funct. Ecol. 17, 237-245.

Woodward, G. (2009). Biodiversity, ecosystem functioning and food webs in fresh waters: Assembling the jigsaw puzzle. Freshw. Biol. 54, 2171-2187.

Woodward, G., and Hildrew, A.G. (2002a). Differential vulnerability of prey to an invading top predator: Integrating field surveys and laboratory experiments. Ecol. Entomol. 27, 732-744.

Woodward, G., and Hildrew, A.G. (2002b). Food web structure in riverine landscapes. Freshw. Biol. 47, 777-798.

Woodward, G., and Hildrew, A.G. (2002c). The impact of a sit-and-wait predator: Separating consumption and prey emigration. Oikos 99, 409-418.

Woodward, G., and Warren, P.H. (2007). Body size and predatory interactions in freshwaters: Scaling from individuals to communities. In: Body Size: The Structure and Function of Aquatic Ecosystems (Ed. by A.G. Hildrew, D. Raffaelli and R. Edmonds-Brown), pp. 98-117. Cambridge University Press, Cambridge. 
Woodward, G., Jones, J.I., and Hildrew, A.G. (2002). Community persistence in Broadstone Stream (U.K.) over three decades. Freshw. Biol. 47, 1419-1435.

Woodward, G., Speirs, D.C., and Hildrew, A.G. (2005a). Quantification and resolution of a complex, size-structured food web. Adv. Ecol. Res. 36, 85-135.

Woodward, G., Ebenman, B., Emmerson, M., Montoya, J.M., Olesen, J.M., Valido, A., and Warren, P.H. (2005b). Body-size in ecological networks. Trends Ecol. Evol. 20, 402-409.

Woodward, G., Perkins, D.M., and Brown, L. (2010a). Climate change in freshwater ecosystems: Impacts across multiple levels of organisation. Philos. Trans. R. Soc. Lond. B 365, 2093-2106.

Woodward, G., Christensen, J.B., Olafsson, J.S., Gislason, G.M., Hannesdottir, E. R., and Friberg, N. (2010b). Sentinel systems on the razor's edge: Effects of warming on Arctic stream ecosystems. Global Change Biol. 16, 1979-1991.

Woodward, G., Blanchard, J., Lauridsen, R.B., Edwards, F.K., Jones, J.I., Figueroa, D., Warren, P.H., and Petchey, O.L. (2010). Individual-based food webs: species identity, body size and sampling effects. Adv. Ecol. Res. 43 (in press).

Wrona, F.J., Prowse, T.D., Reist, J.D., Hobbie, J.E., Lévesque, L.M.J., and Vincent, W.F. (2006). Climate change effects on aquatic biota, ecosystem structure and function. Ambio 35, 359-369.

Yodzis, P. (1988). The indeterminacy of ecological interactions as perceived through perturbation experiments. Ecology 69, 508-515.

Yodzis, P., and Innes, S. (1992). Body size and consumer-resource dynamics. Am. Nat. 139, 1151-1175.

Yoon, I., Williams, R.J., Levine, E., Yoon, S., Dunne, J.A., and Martinez, N.D. (2004). Webs on the Web (WoW): 3D visualization of ecological networks on the WWW for collaborative research and education. Proc. ISandT/SPIE Symp. Electron. Imag., Vis. Data Anal. 5295, 124-132.

Yvon-Durocher, G., Montoya, J.M., Emmerson, M.C., and Woodward, G. (2008). Macroecological patterns and niche structure in a new marine food web. Cent. Eur. J. Biol. 3, 91-103.

Yvon-Durocher, G., Woodward, G., Jones, J.I., Trimmer, M., and Montoya, J.M. (2010a). Warming alters the metabolic balance of ecosystems. Philos. Trans. R. Soc. Lond. B 365, 2117-2126.

Yvon-Durocher, G., Reiss, J., Blanchard, J., Ebenman, B., Perkins, D.M., Reuman, D.C., Thierry, A., Woodward, G., and Petchey, O.L. (2010b). Across ecosystem comparisons of size structure: Methods, approaches, and prospects. Oikos (in press).

Zhang, Y.-P., and Li, X. (2004). The thermal dependence of food assimilation and locomotor performance in southern grass lizards, Takydromus sexlineatus (Lacertidae). J. Thermal. Biol. 29, 45-53.

Zwick, P. (1992). Stream habitat fragmentation-A threat to biodiversity. Biodivers. Conserv. 1, 80-97. 